\title{
The Human Immunodeficiency Virus Coat Protein gp120 Promotes Forward Trafficking and Surface Clustering of NMDA Receptors in Membrane Microdomains
}

\author{
Hangxiu Xu, ${ }^{1 \star}$ Mihyun Bae, ${ }^{1 \star}$ Luis B. Tovar-y-Romo, ${ }^{1}$ Neha Patel, ${ }^{1}$ Veera Venkata Ratnam Bandaru, ${ }^{1}$ \\ Daniel Pomerantz, ${ }^{1}$ Joseph P. Steiner, ${ }^{1}$ and Norman J. Haughey ${ }^{1,2}$ \\ Departments of ${ }^{1}$ Neurology, Richard T. Johnson Division of Neuroimmunology and Neurological Infections and ${ }^{2}$ Psychiatry, The Johns Hopkins University \\ School of Medicine, Baltimore, Maryland 21287
}

Infection by the human immunodeficiency virus (HIV) can result in debilitating neurological syndromes collectively known as HIVassociated neurocognitive disorders. Although the HIV coat protein gp120 has been identified as a potent neurotoxin that enhances NMDA receptor function, the exact mechanisms for this effect are not known. Here we provide evidence that gp 120 activates two separate signaling pathways that converge to enhance NMDA-evoked calcium flux by clustering NMDA receptors in modified membrane microdomains. gp 120 enlarged and stabilized the structure of lipid microdomains on dendrites by mechanisms that involved a redox-regulated translocation of a sphingomyelin hydrolase (neutral sphingomyelinase-2) to the plasma membrane. A concurrent pathway was activated that accelerated the forward traffic of NMDA receptors by a PKA-dependent phosphorylation of the NR1 C-terminal serine 897 (masks an ER retention signal), followed by a PKC-dependent phosphorylation of serine 896 (important for surface expression). NMDA receptors were preferentially targeted to synapses and clustered in modified membrane microdomains. In these conditions, NMDA receptors were unable to laterally disperse and did not internalize, even in response to strong agonist induction. Focal NMDA-evoked calcium bursts were enhanced by threefold in these regions. Inhibiting membrane modification or NR1 phosphorylation prevented gp120 from accelerating the surface localization of NMDA receptors. Disrupting the structure of membrane microdomains after gp120 treatments restored the ability of NMDA receptors to disperse and internalize. These findings demonstrate that gp120 contributes to synaptic dysfunction in the setting of HIV infection by interfering with NMDA receptor trafficking.

\section{Introduction}

Neurocognitive dysfunctions in patients infected with the human immunodeficiency virus (HIV) have continued, despite the wide spread use of combined antiretroviral therapies (CARTs) (Tozzi et al., 2007; Cardenas et al., 2009). Moreover, the prevalence of these symptoms, collectively known as HIV-associated neurocognitive disorders (HANDs), appears to be increasing, perhaps because of accelerated aging in subjects infected with HIV and increased lifespan afforded by CARTs (Antinori et al., 2007; Chang et al., 2008; Valcour et al., 2008; Achim et al., 2009; Brew et al., 2009; Ances et al., 2010). Distinct from the neurocognitive impairments observed before the advent of CARTs, frank dementia or encephalitis are rarely seen in patients on stable CARTs. However, milder forms of cognitive impairment fre-

\section{Received Aug. 8, 2011; revised Sept. 28, 2011; accepted Sept. 29, 2011.}

Author contributions: N.H. designed research; H.X., M.B., L.B.T.-y.-R., N.P., V.V.R.B., D.P., J.P.S., and N.J.H. performed research; L.T.-yR., N.P., J.P.S., and N.H. analyzed data; N.H. wrote the paper.

These studies were supported by NIH Grants MH077542, AG034849, AA0017408, and MH075673 (N.J.H.). We acknowledge Carrie Berlett for technical assistance.

*H.X. and M.B. contributed equally to this work.

Correspondence should be addressed to Norman J. Haughey, Department of Neurology, The Johns Hopkins University School of Medicine, Meyer 6-109, 600 North Wolfe Street, Baltimore, MD 21287. E-mail: nhaughe1@jhmi.edu.

DOI:10.1523/JNEUROSCI.4072-11.2011

Copyright $\odot 2011$ the authors $\quad 0270-6474 / 11 / 3117074-17 \$ 15.00 / 0$ quently occur, despite effective viral control (Simioni et al., 2010). In subjects on stable CARTs, there is evidence of ongoing brain volume loss, white matter injury, hippocampal involvement, metabolic disturbances, synaptic pruning, and dendritic damage that is not associated with treatment failure, viral load, or CD4 counts (Gelman, 2007; Chang et al., 2008; McMurtray et al., 2008; Pelle et al., 2008; Cardenas et al., 2009; Gongvatana et al., 2009; Khanlou et al., 2009; Cohen et al., 2010; McArthur et al., 2010). Together, these observations suggest that CART is not sufficient to prevent neurocognitive damage and that the loss of nerve terminals may be central to the pathogenesis of CART.

The HIV-1 coat protein gp120 is a potent neurotoxin that induces synaptic damage through indirect and direct mechanisms that enhance NMDA receptor activation. Numerous reports have shown that HIV-gp120 upregulates NMDA receptor activity by enhancing the release soluble factors from glia such as arachidonic acid and proinflammatory cytokines (Lipton et al., 1991; Ushijima et al., 1993; Corasaniti et al., 1995; Medina et al., 1999; Catani et al., 2000; Geeraerts et al., 2006). Direct effects of gp120 on neurons that enhance NMDA-evoked calcium flux have also been described, although the mechanisms by which this occurs are not currently understood. Several lines of evidence suggest that a direct enhancement of NMDA receptor activity by gp120 may involve modifications in the spatial location and focal density of NMDA receptors. NMDA receptors can be induced to 
A
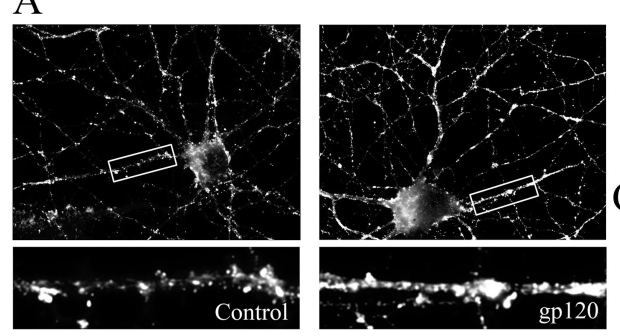

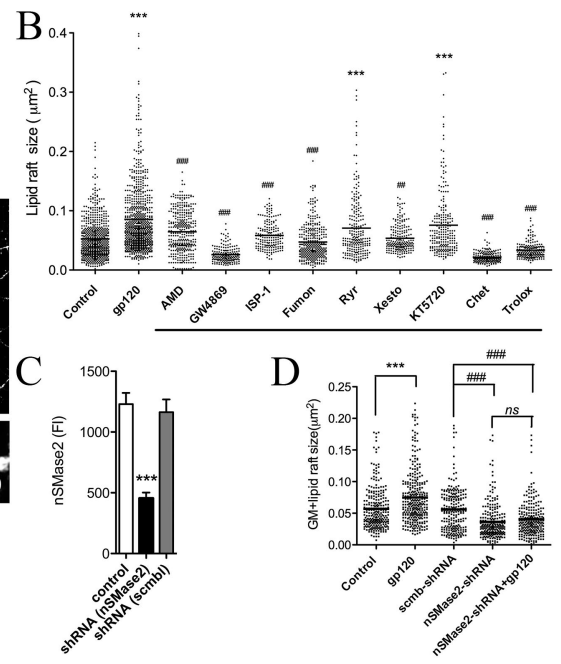

Figure 1. HIV-gp120 increases the size of lipid rafts. Primary hippocampal neurons were treated with gp120 (250 pm) for $6 \mathrm{~h}$, and lipid raft size was determined using a fluorescent probe conjugated to cholera toxin that binds the lipid raft enriched ganglioside GM1.A, Representative images showing that gp 120 increased the size of lipid rafts on neurites (inset shows magnification of the indicated neuritic branch). $\boldsymbol{B}$, Quantitative analysis of lipid raft area showing that gp120-induced increases of lipid rafts size were significantly reduced by a 30 min pretreatment with agents that blocked gp 120 from interacting with the chemokine receptor CXCR4 (AMD3100; $10 \mu \mathrm{M}$ ), sphingomyelin hydrolysis (GW4869; $20 \mu \mathrm{M}$ ), ceramide synthesis (fumonisin B1; $10 \mu \mathrm{M}$ ), de novo ceramide synthesis (ISP-1; $10 \mu \mathrm{M}$ ), IP - $_{3}$-mediated calcium release (xestospongin; $10 \mu \mathrm{M}$ ), PKC (chelerythrine; $1 \mu \mathrm{m}$ ), or scavenging free radicals (trolox; $20 \mu \mathrm{M}$ ). Inhibition of ryanodine receptors (ryanodine; $1 \mu \mathrm{M}$ ) or PKA (KT5720; $0.6 \mu \mathrm{M}$ ) did not prevent gp120 from increasing the size of lipid rafts. Lipid rafts were measured from a minimum of 21 primary neurites derived from three separate experiments; each data point shows the area of a single lipid raft. C, RNA interference reduced protein levels of nSMase2 in primary hippocampal neurons as determined by quantitative immunofluorescence $48 \mathrm{~h}$ after shRNA. A nonsilencing control shRNA lentiviral vector did not alter nSMase2 expression $(n=3)$. $\boldsymbol{D}$, Reduction of nSMase2 expression by RNA interference reduced basal lipid raft size and prevented gp120 from increasing the size of lipid rafts $(n=3) .{ }^{* * *} p<0.001$ compared with control. ${ }^{\# \# \#} p<0.001$ compared with a noncoding scrambled shRNA. ANOVA with Tukey's post hoc comparisons $(\boldsymbol{B}, \boldsymbol{D})$ or Student's $t$ test (C). Cross bars in scatter plots indicate mean, and error bars ( $($ ) are SD.

traffic in or out of lipid rafts with important implications for signal transduction, synaptic plasticity, and cell survival (Füllekrug and Simons, 2004; Haughey et al., 2004; Besshoh et al., 2005; Bandaru et al., 2007, 2009; Wheeler et al., 2009; DelintRamirez et al., 2010). HIV-gp120 increases the size and stabilizes the structure of lipid rafts by increasing ceramide, a critical component of lipid rafts (Haughey et al., 2004; Jana and Pahan, 2004). Ceramide has been implicated in the regulation of synaptic activity through modulation of receptor trafficking and surface expression (Swartz, 2008; Day and Kenworthy, 2009; Owen et al., 2009; Stahelin, 2009; Wheeler et al., 2009). In this study, we sought to determine whether HIV-gp120 enhanced NMDA receptor activity by direct actions on neurons that modify the biophysical properties of membranes to perturb the surface expression and spatial location of NMDA receptors.

\section{Materials and Methods}

Cell culture and experimental treatments. Hippocampal neuronal cultures were prepared from embryonic day 18 Sprague Dawley rats using methods that have been described previously (Haughey et al., 2004). Hippocampi were isolated and trypsinized, and cells were dissociated by gentle tituration in a calcium-free HBSS. Neurons were plated at a density of $150,000 \mathrm{cell} / \mathrm{s} / \mathrm{ml}$ on $15-\mathrm{mm}$-diameter polyethylenimine-coated glass coverslips in Neurobasal media supplemented with B-27 and 1\% antibiotic solution $\left(10^{4} \mathrm{U} / \mathrm{ml}\right.$ penicillin $\mathrm{G}, 10 \mathrm{mg} / \mathrm{ml}$ streptomycin, and $25 \mu \mathrm{g} / \mathrm{ml}$ amphotericin B) in $0.9 \% \mathrm{NaCl}$ (Sigma). Three hours after plating, media was replaced and thereafter supplemented with Neurobasal media containing B-27 every $7 \mathrm{~d}$. Immunofluorescent staining for MAP-2 (neurons) showed that hippocampal cultures were $>98 \%$ neurons; the remainder of cells were predominantly GFAP-expressing astrocytes. Hippocampal cultures were used between 14 and $21 \mathrm{~d}$ in vitro.
HIV-1 coat protein gp $120_{\text {IIIB }}$ was purchased from Advanced Bioscience Laboratories. The protein was aliquoted and stored at $-80^{\circ} \mathrm{C}$ until use and underwent a single free-thaw cycle for each experiment. The chemokine receptor CXCR4 was inhibited with the bicyclam derivative plerixafor hydrochloride AMD3100 (EMD4Biosciences). ER calcium release was inhibited with ryanodine (Tocris Bioscience) and $\mathrm{IP}_{3}$ receptor-mediated calcium release with xestospongin (Tocris Bioscience). Inhibitors of sphingolipid metabolism included antagonists of neutral sphingomyelinase-2 (nSMase2) [GW4869 ( $N, N^{\prime}$-bis[4-(4,5-dihydro-1 $H$-imidazol-2-yl)phenyl]-3,3' - $p$-phenylene-bis-acrylamide dihydrochloride); EMD4Biosciences], serine palmitoyl transferase (myriocin or ISP-1; Sigma), and ceramide synthase (fumonisin B1; EMD4Biosciences). PKA was inhibited with KT5720 [ $(9 S, 10 R, 12 R)-2,3,9,10,11,12$-hexahydro-10-hydroxy-9-methyl-1-oxo-9,12-epoxy$1 H$-diindolo $\left[1,2,3\right.$-fg: $3^{\prime}, 2^{\prime}, 1^{\prime}$-kl] pyrrolo [3,4i] [1,6]benzodiazocine-10-carboxylicacid hexyl ester] (Tocris Bioscience) and PKC with chelerythrine (Tocris Bioscience). Free radicals were scavenged with trolox (Sigma). Lipid raft structures were disrupted by a graded removal of cholesterol from membranes using $\beta$-cyclodextrin (Sigma).

The pGIPZ lentiviral vector containing shRNA for SMPD3 and a noncoding 29-mer scrambled shRNA cassette were obtained from Open Biosystems (catalog \#RMM4431; Thermo Fisher Scientific). The lentiviral vector was cotransfected along with viral packaging plasmids pMDG.2 [pCMV-VSV-G-poly(A) and psPAX2 (pCMV-Gag-Pol); Addgene] into the packaging cell line HEK293T. Virus containing supernatants were collected at 24 and $48 \mathrm{~h}$ after transfection. Virus was concentrated by ultracentrifugation at $90,000 \times g$ for $3 \mathrm{~h}$ at $4^{\circ} \mathrm{C}$, and viral pellets were resuspended in $1.5 \mathrm{ml}$ of sterile $\mathrm{PBS}$ overnight at $4^{\circ} \mathrm{C}$. Viral titer was determined as transducing units per milliliters, and aliquots were stored at $-80^{\circ} \mathrm{C}$. Virus was used at a concentration of four to five viral particles per cell. Target reduction was verified by qRT-PCR for message and by immunofluorescent staining for protein expression.

Mitochondrial membrane potential. Mitochondrial membrane potential was determined in primary hippocampal cultures using JC-1 (5,5'6,6-tetrachloro-1,1'3,3' -tetraethylbenzimidazole carbocyanide iodide) dye (Invitrogen), according to the instructions of the manufacturer. Assays were performed $18 \mathrm{~h}$ after exposure to experimental agents. JC-1 was incubated with cells for $15 \mathrm{~min}$, and fluorescence was read using a Spectramax M2 plate reader (Molecular Devices). Results were normalized so that mean control values were equal to $100 \%$.

Immunofluorescence and confocal microscopy. Labeling of surface located NR1 was accomplished using previously published methods (Washbourne et al., 2004; Wheeler et al., 2009). Hippocampal neurons were exposed to gp120 (100-250 pм) for 1-6 h. Neurons were then incubated for $30 \mathrm{~min}$ at $15^{\circ} \mathrm{C}$ with $5 \% \mathrm{CO}_{2}$ with a mouse monoclonal antibody against the NR1 subunit of the NMDA receptor that recognizes an extracellular epitope located to the $\mathrm{N}$-terminal amino acids 341-561 (R1JHL, 1:50; Affinity BioReagents). A cholera toxin subunit B (CTB) conjugated to Alexa Fluor 555 ( $1 \mathrm{ng} / \mathrm{ml}$; Invitrogen) that binds the ganglioside GM1 (a lipid raft marker) was added during the last 10 min of incubation. We have previously demonstrated that CTB- 555 colocalizes with flotillin, a protein that is known to be located in lipid rafts, and ceramide, a sphingolipid enriched in lipid rafts (Wheeler et al., 2009). Cells were washed three times with ice-cold PBS and fixed with ice-cold $4 \%$ paraformaldehyde in PBS. Nonspecific binding was blocked with 5\% normal goat serum in TBS, followed by a $2 \mathrm{~h}$ incubation at room tem- 

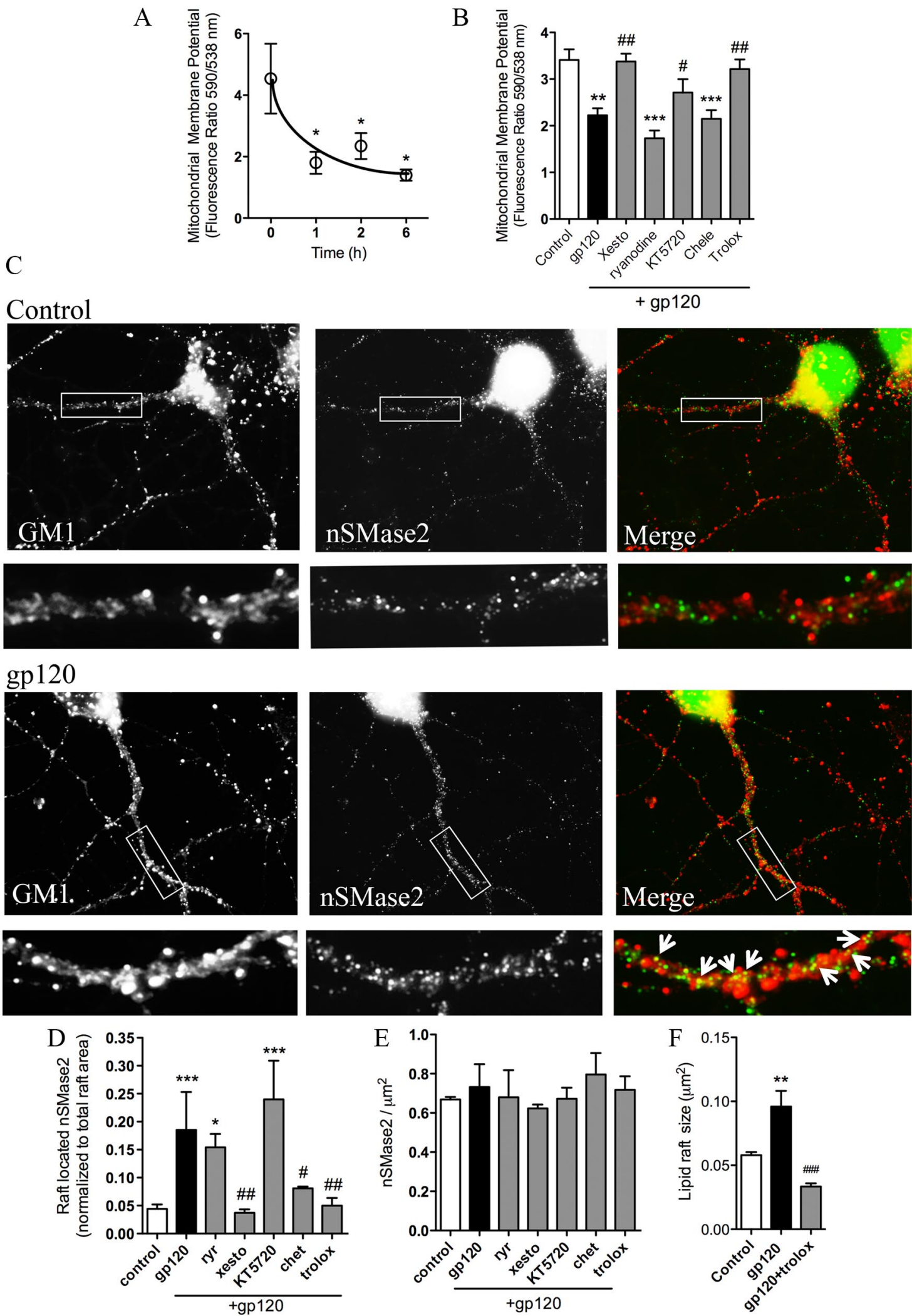

Figure 2. Translocation of neutral sphingomyelinase-2 to lipid rafts required $\mathrm{IP}_{3}$ calcium, mitochondrial depolarization, and protein kinase $C$. Primary hippocampal neurons were treated with gp120 for $6 \mathrm{~h}$ before determinations of mitochondrial membrane potential and spatial location of nSMase2. A, HIV-gp120 (250 pM) significantly decreased mitochondrial membrane potential within $1 \mathrm{~h}$ of exposure ( $n=3$ experiments conducted in duplicates). $\boldsymbol{B}, \mathrm{A} 30$ min pretreatment with inhibitors of $\mathrm{IP}_{3}$ (xestospongin; $10 \mu \mathrm{M}$ ) and PKC (chelerythrine; $1 \mu \mathrm{m}$ ), but not ryanodinesensitive calcium channels (ryanodine; $1 \mu \mathrm{M}$ ), or PKA (KT5720; $0.6 \mu \mathrm{M}$ ) preserved mitochondrial membranes from gp120-induced depolarization ( $n=3$ experiments conducted in duplicates). $C$ Representative immunofluorescent images showing lipid rafts (identified as GM1-expressing domains), nSMase2, and the merged images (GM1 is red, nSMase2 is green, and colocalized regions appear as yellow). Insets show higher magnifications of the indicated neurite. Arrows point to examples of colocalized fluorophores. $\boldsymbol{D}$, Quantitative data showing that gp120 induced nSMase2 to translocate into lipid rafts. Inhibition of $\mathrm{IP}_{3}, \mathrm{PKC}$, and free radical scavenging 30 min before gp 120 prevented translocation of nSMase2 to lipid rafts, whereas inhibition of ryanodine (Figurelegend continues.) 
perature in TBS containing 2.5\% normal goat serum with Alexa Fluor 488 (1:2000; Invitrogen). For standard immunofluorescence, cell were fixed with ice-cold $4 \%$ paraformaldehyde in PBS, and membranes were permeabilized by incubation for $20 \mathrm{~min}$ at room temperature in $0.1 \%$ Triton X-100 in TBS and then incubated for $1 \mathrm{~h}$ in blocking solution containing 2.5\% normal goat serum and $2.5 \%$ normal horse serum in PBS. Cells were incubated with primary antibodies overnight at $4^{\circ} \mathrm{C}$ that included a mouse monoclonal NR1-CT (Millipore) and polyclonal antibodies to NR1 phosphorylated on serine $890\left(\mathrm{NR} 1_{\text {S890 }}\right)$, serine 896 $\left(\mathrm{NR} 1_{\mathrm{S} 896}\right)$, serine $897\left(\mathrm{NR}_{\mathrm{S} 897}\right)$ (each at 1:500; Millipore), and neutral sphingomyelinase 2 (H-195 at 1:250; Santa Cruz Biotechnology). Cultures were washed with TBS and incubated for $2 \mathrm{~h}$ at room temperature with fluorescently tagged secondary antibodies (Alexa Fluor 633, 546, or 488; 1:1000 dilution; Invitrogen). In some experiments, cells were first incubated for 10 min with a CTB conjugated with Alexa Fluor 555 (described in the preceding paragraph) before fixation. Immunopositive puncta on dendritic branches were imaged with a $100 \times$ objective lens using a Carl Zeiss Axiovert 200 microscope equipped with an Orca CCD camera and Improvision imaging software and by confocal microscopy using a Carl Zeiss LSM 510 Meta imaging system.

Immunofluorescent quantification. Quantification of immunofluorescence was conducted using methods similar to those described previously (Wheeler et al., 2009). All images for quantification were taken with identical settings under the same conditions. For each image, the threshold was adjusted manually so that the immunolabeled regions corresponded to puncta with intensities that were at least twofold above the diffuse fluorescence on the dendritic branch. Image quantifications were conducted on single-plane images through the brightest point, and criteria for a positive identification were that the puncta must be clear and distinguishable. Lipid raft size was determined by tracing the boarder of each CTB-555-immunopositive region within a defined region of the dendrite. The numbers of smpd3, NR1, NR1S890, NR1S896, and NR1S897 were determined by counting the number of immunopositive puncta in defined areas of neurites by an investigator blinded to the experimental condition (D.P.). Quantifications were performed on dendrites within $100 \mu \mathrm{m}$ of the soma, and area was calculated for each region of interest by tracing the outline of the dendrite. Calibrations of pixels to square micrometers were accomplished with Open Lab software (Improvision; PerkinElmer Life and Analytical Sciences). Each species of NR1 or smpd 3 were considered to be raft located if there was any pixel overlap between CTB-555 and the secondary antibody Alexa Fluor 488. To account for treatment-induced increases in the size of lipid rafts, the number of colocalized puncta were normalized to the CTB-immunopositive area for each experiment. A minimum of 21 dendrites in at least three separate cultures were quantified for each experimental condition. We confirmed the colocalization data for primary findings with a second method of image quantification. In this method, the dendritic area was defined as described above, and thresholds were set manually for each image at $30 \%$ above background. The numbers of pixels with colocalized fluorescence per square micrometers were determined using Volocity software (Improvision; PerkinElmer Life and Analytical Sciences) and expressed as a ratio to CTB-555 immunopositive pixels.

Detergent-resistant membrane raft isolation. Detergent-resistant membrane rafts were isolated from primary neurons using ice-cold lysis buffer (in mu: 25 Tris $\mathrm{HCl}, 140 \mathrm{NaCl}, 1$ EDTA, 1 PMSF, and $1 \mathrm{Na}_{3} \mathrm{VO}_{4}, \mathrm{pH} 8.0$ ) containing $1.0 \% \mathrm{w} / \mathrm{v}$ CHAPS as the detergent. Lysates were sonicated and incubated on ice for $30 \mathrm{~min}$. After incubation, $333.3 \mu \mathrm{l}$ from the total homogenate was mixed with $666.7 \mu \mathrm{l}$ of $60 \%$ OptiPrep in lysis buffer and

$\leftarrow$

(Figure legend continued.) receptors or PKA were without effect (drug concentrations were the same as indicated for $\boldsymbol{B}$ ). Data are the quantitative analysis of 21 neurites from three separate experiments. $\boldsymbol{E}$, A quantitative analysis of immunopositive puncta showing that gp120 or gp120 plus drug treatments did not alter nSMase2 protein expression. $F$, Inhibiting nSMase2 translocation by scavenging free radicals with trolox also prevented gp 120 from increasing the size of lipid rafts (data are average lipid raft size from a minimum of 21 neurites from 3 separate experiments). ${ }^{*} p<0.05,{ }^{* *} p<0.01,{ }^{* * *} p<0.001$ compared with control. ${ }^{*} p<0.05$, ${ }^{\# \#} p<0.01$, ${ }^{\# \# \#} p<0.001$ compared with gp 120. ANOVA with Tukey's post hoc comparisons. Error bars indicate SD. placed in a $5 \mathrm{ml}$ ultracentrifuge tube. A $0-40 \%$ OptiPrep gradient was formed by layering $1 \mathrm{ml}$ of 35\% OptiPrep in lysis buffer on top of the $1 \mathrm{ml}$ containing homogenate, followed by 30 and $25 \%$ ( $1 \mathrm{ml}$ each), 20\% (0.5 $\mathrm{ml}$ ), and $0 \%$ OptiPrep. The gradient was centrifuged at 47,000 rpm for $18 \mathrm{~h}$ at $4^{\circ} \mathrm{C}$ in a Beckman Coulter MLS-50 swinging bucket rotor. A light scattering band located at the $25-30 \%$ interface was identified, indicating the presence of lipid rafts. Ten $0.5 \mathrm{ml}$ fractions were collected from the top of the ultracentrifuge tube, and proteins were analyzed by immunoblotting. Equal volumes of each fraction were resolved by 10\% SDSPAGE and transferred to PVDF membranes (Bio-Rad). Nonspecific binding sites were blocked with $5 \%(\mathrm{w} / \mathrm{v})$ milk in Tris-buffered saline (in mu: 25 Tris, $150 \mathrm{NaCl}$, and $2 \mathrm{KCl}, \mathrm{pH} 7.4$ ) containing $0.1 \%$ Tween 20 (TBST). After blocking, blots were incubated overnight with the primary polyclonal antibody Flotillin 1 (1:1000; Abcam) or monoclonal antibodies NMDAR1 (1:500; BD Biosciences Pharmingen) and transferrin receptor (1:1000; Invitrogen). After washes with TBST, blots were incubated for $3 \mathrm{~h}$ with the appropriate IgG HRP-linked antibody ( $1: 1000$; Cell Signaling Technology) and developed by enhanced chemiluminescence. Image analysis was performed using a G:BOX Imaging system (Syngene).

Calcium imaging. Cytosolic calcium levels $\left(\left[\mathrm{Ca}^{2+}\right]_{\mathrm{c}}\right)$ were measured using the $\mathrm{Ca}^{2+}$-specific fluorescent probe fura-2 AM. Rat hippocampal neurons were incubated for $20 \mathrm{~min}$ with fura-2 $\mathrm{AM}(2 \mu \mathrm{M})$ at $37^{\circ} \mathrm{C}$ in Neurobasal media containing B-27 supplement. Neurons were washed with Locke's buffer (in mm: $154 \mathrm{NaCl}, 3.6 \mathrm{NaHCO}_{3}, 5.6 \mathrm{KCl}, 1 \mathrm{MgCl}_{2}, 5$ HEPES, $2.3 \mathrm{CaCl}_{2}$, and 10 glucose, $\mathrm{pH}$ 7.4) to remove extracellular fura-2 and incubated at $37^{\circ} \mathrm{C}$ for an additional $10 \mathrm{~min}$ to allow complete deesterfication of the probe. Coverslips containing fura-2-loaded cells were mounted in an RC-26 imaging chamber (Warner Instruments) and maintained at $37^{\circ} \mathrm{C}$ (TC344B Automatic Temperature Controller; Warner Instruments). Neurons were perfused at the rate of $2 \mathrm{ml} / \mathrm{min}$ with Locke's buffer using a V8 channel controller (Warner Instruments). Rapid switching from Locke's buffer to NMDA $(10 \mu \mathrm{M})$ plus glycine (100 $\mathrm{nM}$ ) was accomplished by placing the perfusion tube and suction apparatus close to the cells to be imaged (with a $\sim 0.05 \mathrm{~cm}$ gap) so that a thin film of perfusate rapidly passed over the cells. Some experiments were conducted in the presence of nifedipine $(10 \mu \mathrm{M})$ to prevent depolarizationinduced activation of voltage-sensitive calcium channels. Cells were excited at 340 and $380 \mathrm{~nm}$, and emission was recorded at $510 \mathrm{~nm}$ with a video-based intracellular imaging system (Photon Technology) equipped with a QuantEM 512sc electron-multiplying gain camera (Photometrics). Images were acquired at the rate of $200 \mathrm{~ms}$ per image pair from $10-15$ circular regions $(1 \mu \mathrm{m}$ in diameter) along dendritic branches. The fluorescent intensities of ratio images were converted to nanomolar $\left[\mathrm{Ca}^{2+}\right]_{\mathrm{c}}$ by curve fitting using reference standards as described previously (Wheeler et al., 2009). In some experiments, cells were fixed after calcium recordings and immunostained as described in the section on immunofluorescence with CTB-555 and NR1. These images were used for direct comparisons of focal NMDA-evoked calcium responses with the location of NR1 to lipid raft or non-raft microdomains.

\section{Results}

\section{HIV-gp120 increases lipid raft size by mechanisms that involve the sphingomyelin hydrolase nSMase2}

In these studies, we used a strain of gp120 (gp120 $\left.{ }_{\text {IIIB }}\right)$ that interacts with the chemokine receptor CXCR4. Although CCR5 trophic strains of HIV are thought to be the predominant viral species resident in brain (because of their ability to productively infect microglia and macrophages), several lines of evidence suggest that CXCR4 trophic strains of HIV play important roles in the pathogenesis of HANDs. For instance, CXCR4 and dual trophic strains of HIV have been isolated from brain, suggesting that tropism rather than coreceptor usage may be critical for brain infection (Gorry et al., 2001). Additionally, HIV-infected monocytes containing CXCR4 trophic virus intermittently traffic from the periphery into the CNS, and this traffic is enhanced when T-cells become activated or the integrity of the blood-brain 

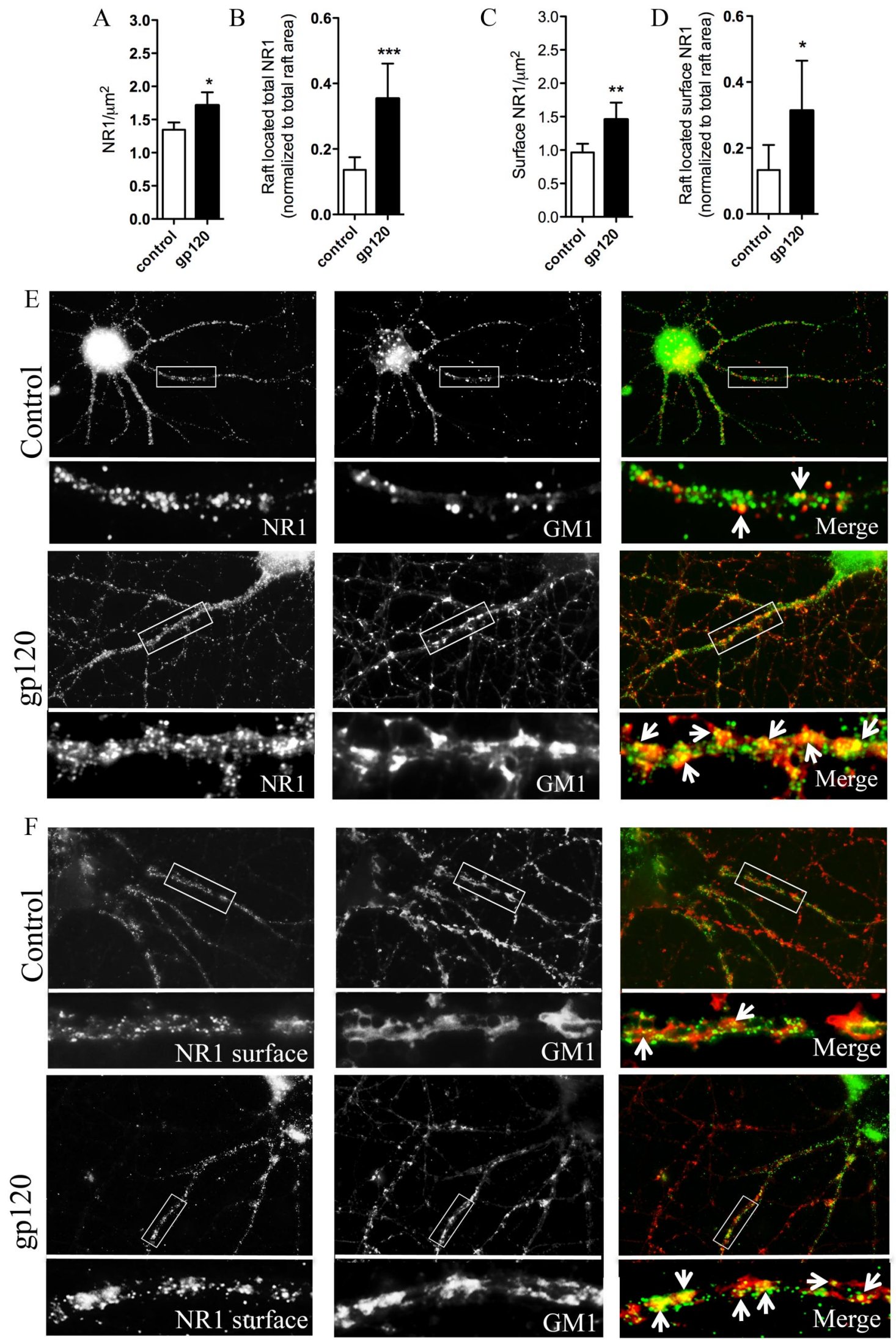

Figure 3. Increased lipid raft and surface localization of NR1 after exposure of hippocampal neurons to gp120. Primary hippocampal neurons were treated with gp 120 (250 pM) for $6 \mathrm{~h}$, and NR1 localization was determined by immunohistochemistry to detect total or surface-located NR1. (A) Quantitative analyses of total NR1 showing that gp120 induced a small but significant increase in total NR1 $(\boldsymbol{A})$ and a large increase in NR1 that was localized to lipid raft domains $(\boldsymbol{B})$. Quantitative analysis of surface-located NR1 showing that gp120 increased surface expression of NR1 $(\boldsymbol{C})$ with prominent increases in surface NR1 that localized to lipid rafts (D). Data are the quantitative analysis of a minimum 21 neurites from 3 separate experiments. ${ }^{*} p<0.05,{ }^{* *} p<0.01,{ }^{* * *} p<0.001$ compared with control. Student's $t$ tests. Error bars indicate SD.E, $\boldsymbol{F}$, Representative images of primary hippocampal neurons immunopositive for total NR1, surface-located (Figure legend continues.) 
A control

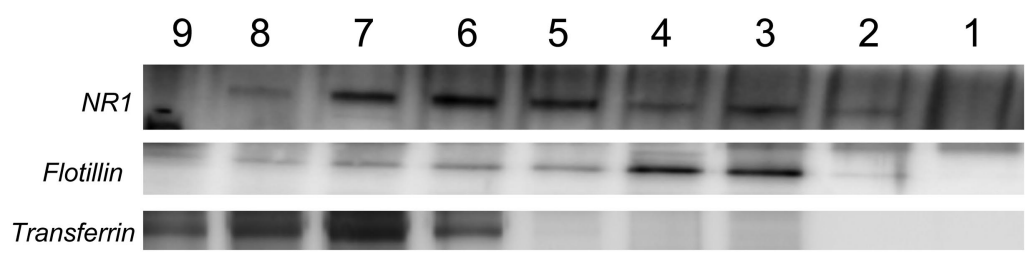

$\mathrm{B}$ gp120

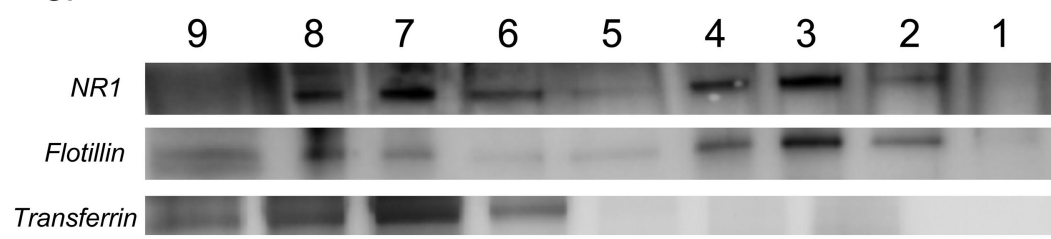

Figure 4. HIV-gp120 promotes the localization of NR1 to lipid rafts. Primary hippocampal neurons were exposed to vehicle or gp120 (250 pм) for $6 \mathrm{~h}$, and the location of NR1 was determined by density centrifugation of detergent-extracted membranes. $\boldsymbol{A}$, Immunoblot showing that, in control conditions, NR1 was primarily located to more dense fractions that were also immunopositive for transferrin, a glycoprotein known to be located outside of lipid rafts. $\boldsymbol{B}$, After exposure to gp 120, NR1 was prominently located to more buoyant fractions that were also immunopositive for the lipid raft marker flotillin. The density location of transferrin was not altered after gp120 treatments. Immunoblots are representative of three independent experiments with similar results.

increased lipid platform size. gp120 binding to CXCR4 is known to promote ER calcium release through a rapid hydrolysis of phospholipase $\mathrm{C}$ to generate $\mathrm{IP}_{3}$ and diacylglycerol (DAG). Both calcium and DAG are cofactors for PKC activation (Dreyer et al., 1990; Pandey and Bolsover, 2000; Höke et al., 2009). Therefore, we inhibited $\mathrm{IP}_{3}$-mediated calcium release or PKC and found that gp120 was unable to increase the size of lipid raft domains (Fig. $1 B)$. Inhibition of ryanodine-sensitive ER calcium release or PKA did not prevent gp120 from increasing the size of lipid rafts (Fig. $1 B$ ). These data suggest that gp120 acted through CXCR4 to increase lipid raft size by mechanisms that involved $\mathrm{IP}_{3}$-mediated calcium release and PKC.

HIV-gp120 increases ceramide by activating the sphingomyelin-hydrolyzing enzyme nSMase2 (Haughey et al., 2004; Jana and Pahan, 2004). To determine whether ceramide generation was required for gp120 to increase the size of

barrier is compromised by inflammation, drug abuse, or immune reconstitution inflammatory syndrome (Liu et al., 2000; Miller et al., 2004; Gray et al., 2005; El-Hage et al., 2006; Dhillon et al., 2008; Fischer-Smith et al., 2008; Ramirez et al., 2009; Yao et al., 2011).

HIV-gp120 increases ceramide in neurons by mechanisms that involve the sphingomyelin-catabolizing enzyme nSMase2 (Haughey et al., 2004; Jana and Pahan, 2004). Because ceramide is an abundant and critical component of lipid rafts, we first determined whether gp120 promoted the formation of these domains in the dendrites of primary neurons. In initial dose and time course experiments, we exposed hippocampal neurons to gp120 (100$500 \mathrm{pm}$ ) for up to $24 \mathrm{~h}$ and quantified the size of GM1immunopositive lipid platforms. We have shown previously that GM1 localizes with the lipid raft markers ceramide and flotillin in neurons (Wheeler et al., 2009). In initial dose and time course experiments, we found that a $6 \mathrm{~h}$ exposure of neurons to HIVgp120 (250 pM) consistently increased the size of lipid platforms. Shorter time points ( 2 min to $2 \mathrm{~h}$ ) and lower doses of gp120 (50 and $100 \mathrm{pm}$ ) did not significantly increase the size of lipid platforms within $6 \mathrm{~h}$ (data not shown). Therefore, a $250 \mathrm{pm}$ dose of gp120 and exposure time was used for all subsequent experiments unless otherwise indicated. gp120 did not appreciably alter the number of lipid rafts but increased the size of lipid rafts by $48.2 \pm 9.1 \%$, from $56.4 \pm 9.2$ to $83.5 \pm 21.1 \mathrm{~nm}^{2}$ (Fig. $1 A, B$ ). Inhibition of the chemokine receptor CXCR4 with the bicyclam derivative plerixafor hydrochloride (AMD3100) prevented gp120 from increasing lipid raft size, consistent with known actions of this strain of gp120 to bind and activate CXCR4 (Toth et al., 2004) (Fig. 1 B). We next followed signaling downstream from CXCR4 to identify the molecular mechanisms by which gp120

$\leftarrow$

(Figure legend continued.) NR1, lipid rafts (identified by GM1), and the merged images (NR1 is green, GM1 is red, and colocalized images appear yellow). Insets are magnifications of the indicated neurites. Images show that, under control conditions, a small amount of total and surface NR1 are located to lipid rafts. A $6 \mathrm{~h}$ treatment with gp 120 increased the size of lipid rafts, total NR1, and surface NR1. NR1 appeared to cluster in lipid rafts. Arrows point to examples of total $(\boldsymbol{E})$ and surface $(\boldsymbol{F})$ NR1 that are localized to GM1. lipid rafts, we blocked hydrolytic, salvage, or de novo pathways of ceramide generation before addition of gp120 to cultures. Inhibition of nSMase2 (a hydrolytic pathway), serine palmitoyl transferase (the rate-limiting enzyme in de novo ceramide synthesis), and fumonisin B1 (an inhibitor of ceramide synthases in the salvage pathway) each prevented gp120 from increasing the size of lipid rafts (Fig. $1 B$ ), suggesting that multiple pathways of ceramide generation become activated within $6 \mathrm{~h}$ of exposures to gp120. We tested each of these antagonists in the absence of gp120 and found that only inhibition of nSMase2 (with GW4869) reduced the size of lipid rafts (data not shown), suggesting that this enzyme is essential to maintain the basal structure of these membrane domains. We confirmed a central role for nSMase 2 in gp120-induced increases of lipid raft size using RNA interference. A reduction in $n$ SMase 2 expression was validated by qRT-PCR for message $(0.88 \pm 0.026$ at $24 \mathrm{~h}, 0.11 \pm 0.032$ at $48 \mathrm{~h}$, and $0.16 \pm 0.024$ at $48 \mathrm{~h}$ compared with controls) and by immunofluorescence for protein (Fig. $1 C$; data shown are $48 \mathrm{~h}$ after transfections). Lentiviral-delivered shRNA to block nSMase 2 expression reduced the size of lipid rafts in the absence of gp 120 and prevented gp120 from increasing lipid raft size (Fig. 1D).

\section{Increased lipid raft size involves redox-sensitive translocation} of nSMase 2

Based on findings that gp120 increases cellular oxidation (Corasaniti et al., 2000) and data that nSMase 2 traffics to the plasma membrane in response to oxidative stress (Levy et al., 2006), we next determined whether oxidative stress contributed to increased lipid raft size by promoting the translocation of nSMase2. HIV-gp120 progressively decreased mitochondrial membrane potential (over a time period of $6 \mathrm{~h}$ ) by mechanisms that involved $\mathrm{IP}_{3}$-mediated calcium release and PKC (Fig. $2 A, B$ ). HIV-gp120 increased the fraction of nSMase 2 that located to lipid rafts from $4.4 \pm 0.7 \%$ in control neurons to $26.5 \pm 1.0 \%$ in neurons exposed to gp120, with no apparent increase in total nSMase2 (Fig. 2C-E). Inhibition of $\mathrm{IP}_{3}$-mediated calcium release, $\mathrm{PKC}$, and scavenging free radicals prevented gp120 from inducing the translocation of nSMase 2 to the plasma membrane 


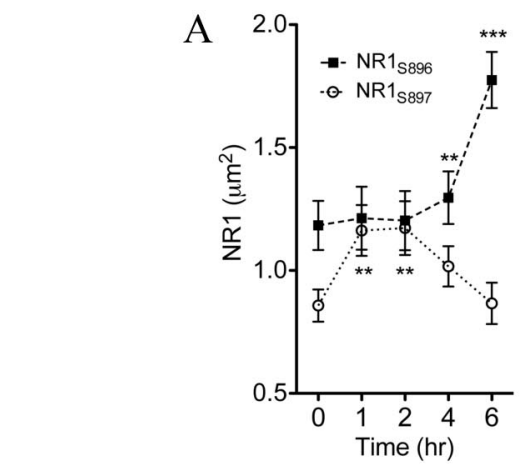

B
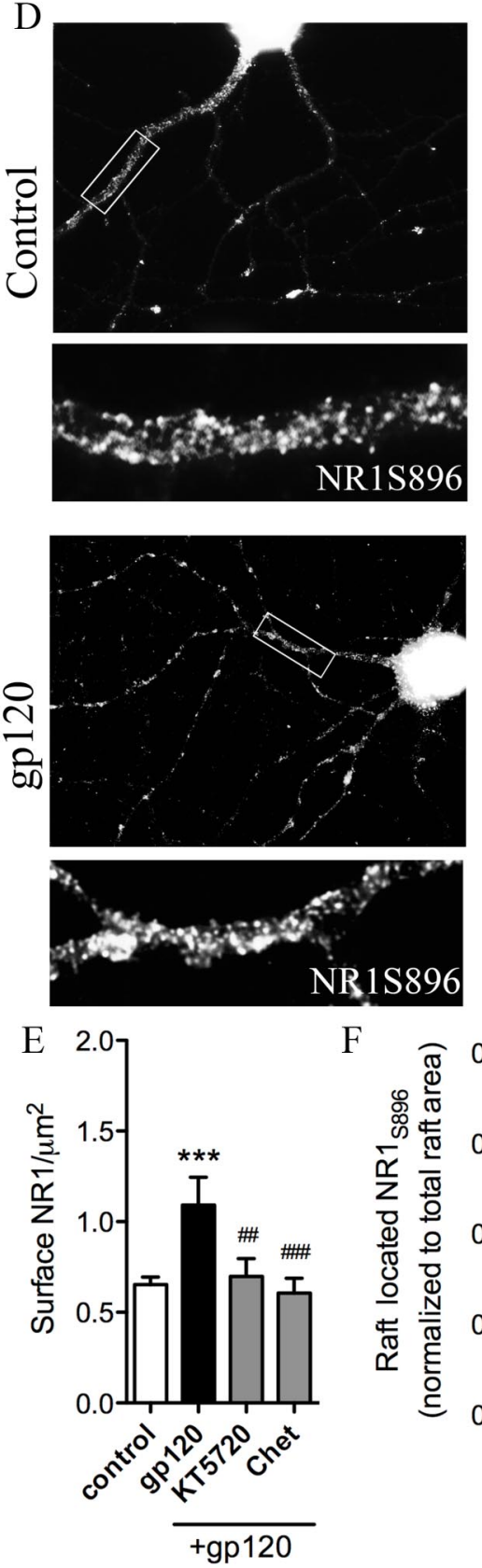

F
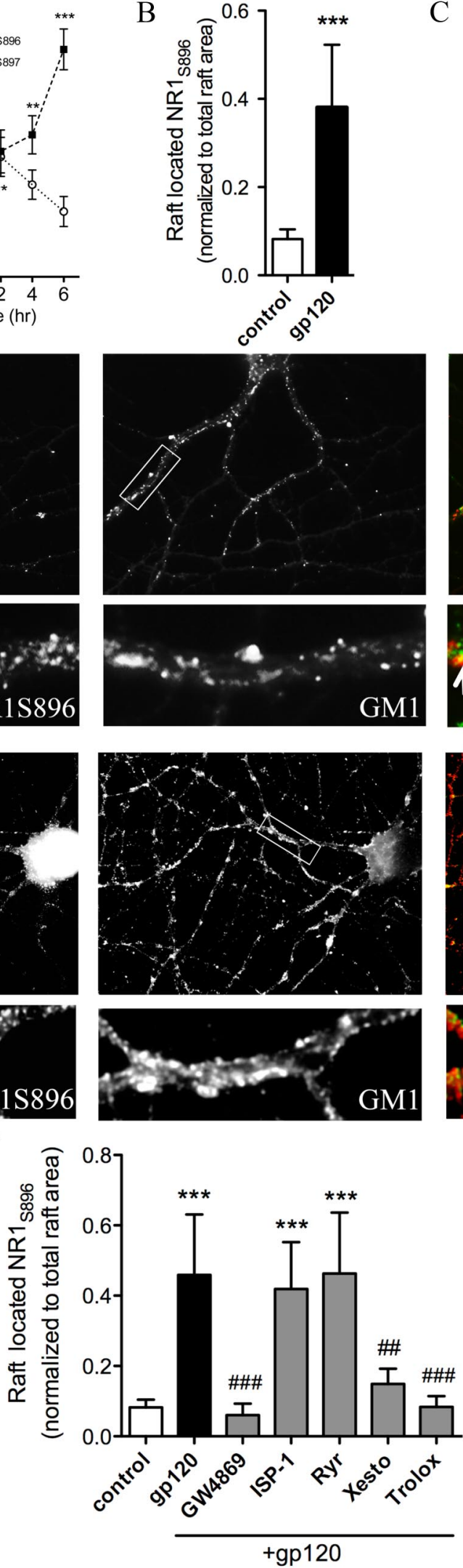
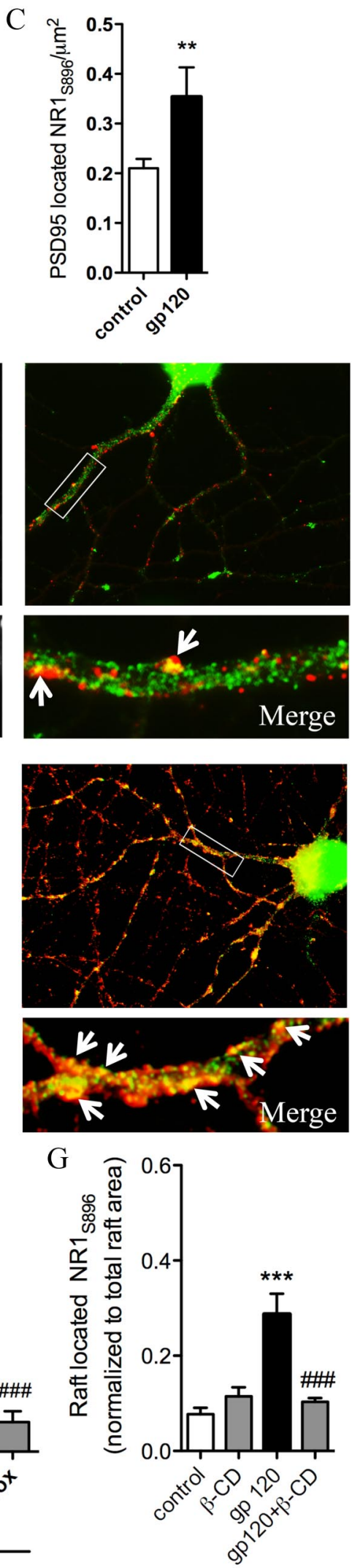

Figure 5. gp120 induces a sequential phosphorylation of serine residues 897 and 896 on NR1 to promote the forward traffic of NR1 to lipid raft structures. Primary hippocampal neurons were treated with gp $120(250 \mathrm{pm})$ for $0-6 \mathrm{~h}$, and the amount of NR1 with phosphorylations on serines 897 and 896 were determined by quantitative immunofluorescence. $\boldsymbol{A}$, Phosphorylation of NR1 on serine $897\left(\mathrm{NR}_{5897}\right)$ increased within $1 \mathrm{~h}$ and declined to basal levels within $4 \mathrm{~h}$ after gp120 exposures. Phosphorylation of NR1 on serine 896 (NR1 $1_{5896}$ ) gradually increased within $2-6 \mathrm{~h}$ after exposure of neurons to gp120. $\boldsymbol{B}, \mathrm{A} 6 \mathrm{~h}$ treatment with gp120 resulted in a large increase of NR1 phosphorylated on serine 896 that located to lipid rafts. $\boldsymbol{C}$, gp 120 increased the amount of NR1 $1_{\mathrm{S} 896}$ that colocalized with PSD95. D, Examples of immunofluorescent images showing NR1 phosphorylated on serine 896 , lipid rafts (identified by GM1), and the merged images (phosphorylated NR1 s896 $_{2}$ is green, GM1 is red, and colocalized images appear yellow) showing that a small fraction of NR1 with phosphorylation on serine 896 were located to lipid rafts in control (Figure legend continues.) 
or increasing lipid rafts size (Fig. 2D,F). The pharmacological agents used in these experiments did not themselves alter the cellular location of nSMase2 (data not shown). Together, these data suggest that gp120 increased the size of lipid rafts by redoxsensitive and PKC-dependent translocation of nSMase2 to the plasma membrane.

\section{gp120 increases the surface expression of and clustering of NR1 into lipid rafts}

Rapid and transient increases of ceramide mediated by nSMase 2 can regulate the fusion and insertion of NMDA receptors with the plasma membrane (Wheeler et al., 2009). Because gp120 promotes a slow and sustained increase of ceramide (Haughey et al., 2004; Jana and Pahan, 2004), we next determined whether this pattern of ceramide accumulation modified the location and surface expression of NMDA receptors. Using antibodies directed against the NR1 subunit, we found that a $6 \mathrm{~h}$ treatment with gp120 increased total NR1 by $25.9 \pm 2.23 \%$ and increased NR1 located to lipid rafts by $278.1 \pm 40.3 \%$ (Fig. $3 A, B$ ). In these studies, the amount of NR1 that located to lipid rafts was normalized to total raft area. These findings suggest that gp120 actively promoted the localization of NR1 to lipid rafts and was not simply a function of increased lipid raft size. NR1 that was present in lipid rafts appeared as clusters (two or more puncta with overlapping pixels) and was more often punctate when located to nonraft regions of the membrane (Fig. 3E). Because NR1 could have been located at or below the cell surface in these experiments, we next determined whether gp120 increased the surface expression of NR1 using an antibody that recognizes the $\mathrm{N}$ terminal of NR1 and an immunochemical technique that selectively identifies NR1 present at the outer surface of the plasma membrane (Washbourne et al., 2004; Wheeler et al., 2009). In cultures exposed to gp120, surface NR1 was increased by $52.1 \pm 15.4 \%$ (Fig. 3C), and lipid-raft-located surface NR1 was increased by $175.2 \pm 12.7 \%$, after normalizing to total lipid raft area (Fig. 3D). Similar to total NR1, these surface-located NR1 appeared as clusters when localized to lipid rafts domains and punctate when located to non-raft regions of the membrane (Fig. $3 F$ ). These data demonstrate that gp120 enhanced the forward traffic and surface expression of NR1.

We further confirmed that gp120 promoted the lipid raft localization of NR1 using biochemical methods to separate detergent-soluble and detergent-resistant membranes from primary neuronal cultures followed by isolation on a density gradient. The tight packing of lipids in lipid rafts prevents detergent

$\leftarrow$

(Figure legend continued.) cultures. A 6 h exposure to gp120 increased NR1 with phosphorylation on serine 896 that was prominently clustered into lipid raft domains. Insets show higher magnifications of the indicated neurites. Arrows point to regions in which $N R 1_{5896}$ is colocalized with GM1. $\boldsymbol{E}$, A quantitative analysis of surface-located NR1 showing that inhibition of PKA (KT5720; $0.6 \mu \mathrm{M}$ ) or PKC (chelerythrine; $1 \mu \mathrm{M}$ ) prevented gp120 from increasing NR1 surface localization, suggesting that phosphorylations of serines 897 and 896 were important for surface localization of NR1. $F$, A 30 min preincubation with drugs to block sphingomyelin hydrolysis (GW4869; $20 \mu \mathrm{m}$ ), IP ${ }_{3}$-mediated calcium release, or a free radicals scavenger (trolox; $20 \mu \mathrm{m}$ ), but not inhibitors of de novo ceramide synthesis (ISP-10 $\mu \mathrm{M}$ ) or ryanodine receptors (ryanodine; $1 \mu \mathrm{M}$ ), prevented phosphorylated NR1 $1_{5896}$ from accumulating in lipid rafts (these same agents prevented gp120 from enlarging lipid rafts; see Fig. 1). $G$, Disrupting the structure of lipid rafts with $\beta$-cyclodextrin $(\beta-C D ; 15 \mu \mathrm{m})$ after gp120-induced clustering of $\mathrm{NR}_{5896}$ into lipid rafts resulted in a dispersion of these receptor subunits. Data were derived from the quantitative analyses of at least 21 neurites from three separate experiments. ${ }^{*} p<0.05$, ${ }^{* *} p<0.01$, ${ }^{* * *} p<0.001$ compared with control, ${ }^{*} p<0.05,{ }^{\# \#} p<0.01,{ }^{\# \# \#} p<0.001$ compared with gp120. Student's $t$ tests. Error bars indicate SD. incorporation into the membrane, and thus these regions are resistant to detergent solubilization. Immunoblotting analysis of the resulting fractions showed that in control cultures NR1 was primarily located to more dense non-raft regions that were immunopositive for transferrin (a non-raft located protein), with small amounts of NR1 located to the more buoyant lipid raft fractions that were immunopositive for flotillin (a lipid-raftassociated protein). After a 6 h exposure to gp 120 , the majority of NR1 became located to lipid raft fractions, with smaller amounts located to the non-raft fractions. HIV-gp120 did not alter the location of transferrin (Fig. 4).

\section{HIV-gp120 accelerates the forward traffic of NR1 by enhancing the coordinated phosphorylation of two NR1 C-terminal serine residues}

Phosphorylation of the NR1 C-terminal has been shown to regulate trafficking of NMDA receptors. In particular, phosphorylation of NR1 by PKA on serine 897 and PKC on serine 896 accelerated the forward traffic and surface expression of NMDA receptors by suppressing an endoplasmic reticulum retention signal (Agr-X-Arg motif) located on the NR1 C terminal. Based on findings that gp 120 enhances activity of both PKA and PKC through differential G-protein subunit signaling (Gupta et al., 1994; Zheng et al., 1999; Masci et al., 2003), we determined whether gp120 accelerated the forward traffic of NR1 by enhancing the phosphorylation of C-terminal serines on NR1. HIVgp120 transiently increased phosphorylation of NR1 on serine 897 within $1 \mathrm{~h}$ after gp 120 exposure (Fig. 5A). Phosphorylation of serine 896 progressively increased between 4 and $6 \mathrm{~h}$ (Fig. $5 A$ ). In cultures exposed to gp 120 for $6 \mathrm{~h}$, the amount of NR1 phosphorylated on serine 896 that located to lipid rafts increased by $417.7 \pm 130.8 \%$ (normalized to account for increased lipid raft area; Fig. $5 B$ ), suggesting that the majority of NR1 located to lipid rafts was phosphorylated on serine 896. NR1 phosphorylated on serine 896 was primarily localized with PSD95, suggesting a synaptic targeting (Fig. 5C). NR1 serine 896 appeared as clusters when located to lipid raft domains and punctate in appearance when located to non-lipid raft regions of the membrane (Fig. $5 D$ ). We also observed that the size of clusters containing NR1 phosphorylated on serine 896 was increased after gp120 treatment (Fig. 5D). To identify the kinases responsible for these phosphorylations, we first inhibited PKC before exposure of neurons to gp120 and found that phosphorylation of NR1 on serine 896 was inhibited but phosphorylation of NR1 on serine 897 was unaffected. When we first inhibited PKA before exposure to gp120, phosphorylation of NR1 on both serines 897 and 896 was inhibited (data not shown). Either PKA or PKC inhibition was sufficient to prevent gp120 from increasing NR1 surface expression (Fig. 5E). These data suggest that gp120 accelerated the forward traffic and surface expression of NR1 by mechanisms that include phosphorylations of NR1 on serine 897 and serine 896 .

\section{Lateral movement and endocytosis of NMDA receptors is inhibited by stabilized lipid raft structures}

The insertion and surface expression of NMDA receptors is counterbalanced by constitutive and agonist-induced receptor internalization. Therefore, we determined whether the stabilization and enlargement of lipid rafts interfered with NR1 internalization. Blocking the mechanisms that increased lipid raft size, namely, $\mathrm{IP}_{3}$-mediated ER calcium release, nSMase2 and free radical scavenging also prevented the accumulation of NR1 phosphorylated on serine 896 in lipid rafts (Fig. 5F). Drugs used in these experiments did not themselves alter the amount of NR1 

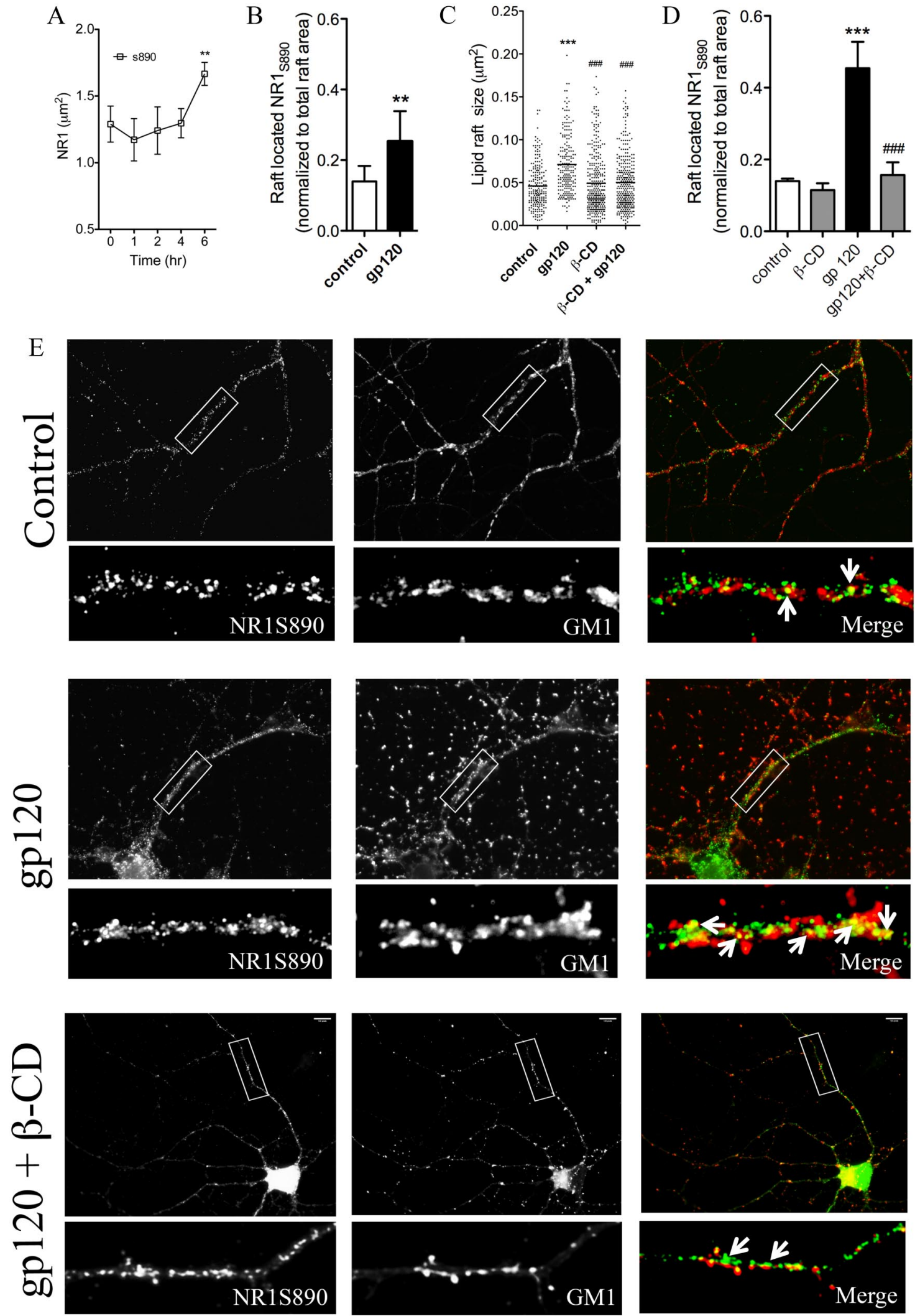

Figure 6. Phosphorylation of NR1 on serine 890 was unable to disperse NR1 clusters after gp 120 treatment. Hippocampal neurons were treated with gp 120 ( $250 \mathrm{pm})$ for up to $6 \mathrm{~h}$, and the number and location of phosphorylated NR1 ${ }_{5890}$ was determined by quantitative immunohistochemistry. $A$, Phosphorylation of NR1 $1_{5890}$ was increased between 4 and $6 \mathrm{~h}$ after exposures of neurons to gp120. $B$, The number of phosphorylated NR1 $1_{5890}$ that localized to lipid rafts significantly increased after $6 \mathrm{~h}$ of exposure to gp120. Disrupting lipid raft structure with $\beta$-cyclodextrin ( $\beta$-CD; $15 \mu \mathrm{M}$; this drug extracts cholesterol from plasma membranes) reversed gp120-induced increases of lipid raft size $(\boldsymbol{C})$ and reversed the clustering of NR1 $1_{5890}$ into lipid rafts (D). $\boldsymbol{E}$, Representative immunofluorescent images of hippocampal neurons showing NR1 phosphorylated on serine 890 (NR15890), lipid rafts (identified by GM1), and the merged images (NR1S890 is green, GM1 is red, and colocalized regions appear yellow). In control cultures, NR1phosphorylated on serine 890 were diffusely distributed along neurites with little localization to lipid rafts. After a $6 \mathrm{~h}$ treatment with gp 120, the number of NR1 phosphorylated on seine 890 increased and was often located in small clusters associated with lipid rafts. Arrows point to regions in which NR1 ${ }_{\text {s890 }}$ (Figure legend continues.) 
A
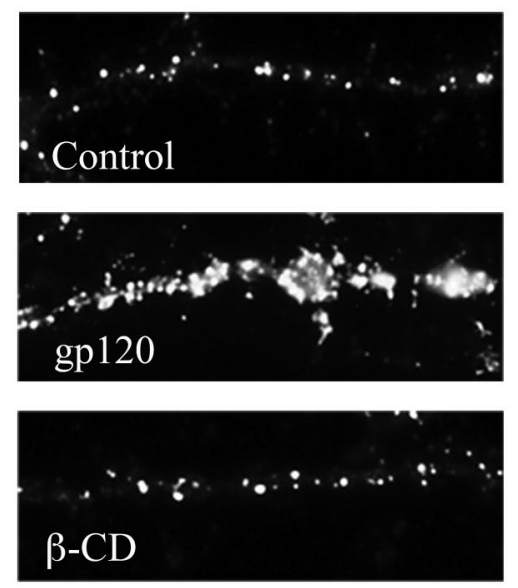
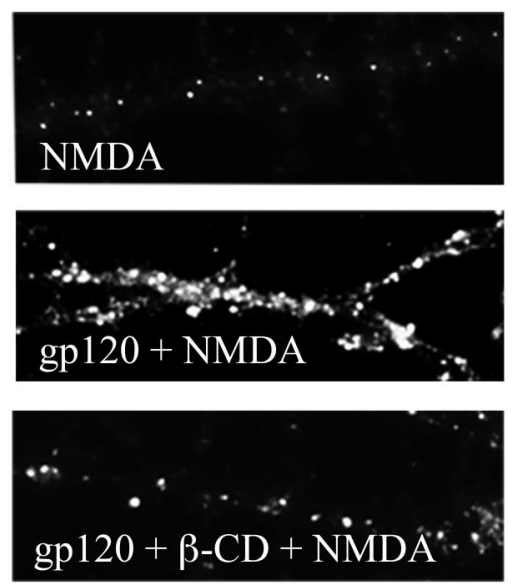

B

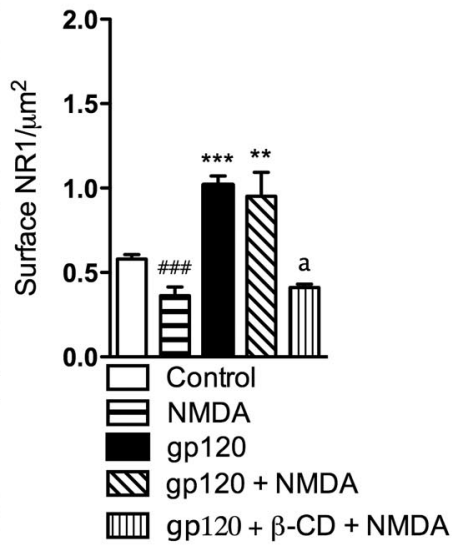

Figure 7. Agonist-induced internalization of NMDA receptors is inhibited after gp120 treatment by mechanisms that are dependent on the physical properties of lipid rafts. $A$, Representative images showing surface-located NR1 on primary hippocampal neurons. Left column shows surface NR1 in control conditions, after a $6 \mathrm{~h}$ treatment with gp120 ( $250 \mathrm{pm)} \mathrm{or} \mathrm{a} 30 \mathrm{~min}$ treatment with $\beta$-cyclodextrin ( $\beta$-CD; $15 \mu \mathrm{m})$. Right column shows surface NR1 after a 45 min exposure to NMDA (10 $\mu \mathrm{m})$ plus glycine (100 $\mathrm{nm})$ in control conditions, after a $6 \mathrm{~h}$ treatment with gp 120, or after a $6 \mathrm{~h}$ treatment with gp 120 followed by a 30 min treatment with $\beta$-cyclodextrin. $B$, Quantitative data showing that a 45 min treatment with NMDA plus glycine reduced surface NR1 in control conditions. A $6 \mathrm{~h}$ treatment with gp120 increased surface NR1 and prevented agonist-induced internalization of NR1. Disrupting the structure of lipid rafts with $\beta$-cyclodextrin after gp120 treatment restored agonist-induced internalization of NR1. Data show the average number of NR1 standardized to neurite area derived from a minimum 21 neurites per condition. Error bars indicate SD. ${ }^{* *} p<0.01$, ${ }^{* * *} p<0.001$ compared with control. ${ }^{\# \# \#} p<0.001$ compared with gp120 and ${ }^{a} p<0.001$ compared with gp120 plus NMDA. ANOVA with Tukey's post hoc comparisons.

serine 896 located to lipid rafts in the experimental timeframe (data not shown). Likewise, disrupting the structure of lipid rafts with $\beta$-cyclodextrin after gp120 treatments reduced the amount of NR1 phosphorylated on serine 896 that was located to lipid rafts (Fig. 5G) and reduced the size of lipid rafts (data not shown), suggesting that the enlargement and stabilization of these membrane microdomains by gp120 sequestered NMDA receptors.

Additional evidence that stabilization of lipid rafts played a role in sequestering NMDA receptors was provided by studying the effects of gp120 on the phosphorylation of NR1 serine 890, a modification important for the dispersal of NMDA receptor clusters (Tingley et al., 1997). Within $6 \mathrm{~h}$ of gp120 treatment, the phosphorylation of NR1 on serine 890 was increased by $61 \pm$ $4.0 \%$ (Fig. $6 A$ ), and localization to lipid rafts increased by $132.4 \pm$ $24.9 \%$ (normalized for increased raft area; Fig. $6 \mathrm{~B}$ ). In control cultures, NR1 phosphorylated on serine 890 appeared punctate in all regions of the membrane, consistent with a role in the dispersal of NMDA receptor clusters (Fig. 6E). After gp120 treatment, NR1 phosphorylated on serine 890 appeared as small clusters in lipid platforms and was punctate in non-platform regions of the membrane (Fig. $6 E$ ). Disrupting the structure of lipid rafts with $\beta$-cyclodextrin after gp120 treatments reduced the size of lipid platforms (Fig. 6C,E), and NR1 serine 890 no longer appeared to be clustered (Fig. $6 D, E$ ).

We next determined whether the internalization of NMDA receptors was perturbed after gp120 treatments. NMDA receptors undergo agonist-induced internalization in response to NMDA plus glycine (Nong et al., 2003), but at much slower rates than AMPA receptors. In control conditions, $37.6 \pm 6.8 \%$ of

\section{$\leftarrow$}

(Figure legend continued.) is localized to GM1. Disrupting the structure of lipid rafts with $\beta$-cyclodextrin after a $6 \mathrm{~h}$ exposure to gp 120 reduced the size of lipid rafts and redistributed NR1 phosphorylated on serine 890 along neurites. Arrows point to regions in which clusters of $N R 1_{8890}$ are located to non-raft regions. Data were derived from the quantitative analyses of at least 21 neurites from three separate experiments. ${ }^{* *} p<0.01$, ${ }^{* * *} p<0.001$ compared with control. ${ }^{\# \#} p<0.001$ compared with gp 120.A, D,E, AVONA with Tukey's post hoc comparisons. $B, C$, Student's $t$ tests. Error bars indicate SD. surface NR1 were internalized within $1 \mathrm{~h}$ after applications of glycine plus NMDA. Pretreatment of neurons with gp120 reduced the agonist-induced internalization of NR1 to $6.52 \pm$ $2.3 \%$. Disrupting the structure of lipid rafts with $\beta$-cyclodextrin after gp120 treatments restored agonist-induced internalization to $29.1 \pm 2.7 \%$ (Fig. $7 A, B$ ). $\beta$-Cyclodextran did not itself alter the surface expression of NR1 (data not shown). These data suggest that the stabilization and enlargement of lipid rafts prevented the lateral dispersal and internalization of NMDA receptors.

NMDA receptor surface clustering enhances the amplitude of focal NMDA-evoked calcium bursts

Calcium flux through NMDA receptors regulates numerous signaling pathways from synaptic plasticity to apoptosis through signals coded in temporal and spatial calcium bursts. Therefore, we determined whether the sequestration of NMDA receptors into lipid platforms after gp120 treatments altered NMDAevoked calcium bursts using a rapid imaging technology (200 ms/image pair) that focused on discrete microdomains $(\sim 1$ $\mu \mathrm{m}^{2}$ ). A brief application of NMDA/glycine evoked calcium bursts with the majority $(81.7 \pm 9.6 \%)$ of peak calcium spikes in the 250-500 nM range. None of the calcium spike amplitudes were above $1000 \mathrm{~nm}$, and few were above $500 \mathrm{~nm}$ (Fig. 8 A, Table 1). A $6 \mathrm{~h}$ exposure to gp120 shifted the amplitude of calcium spikes so that few $(7.2 \pm 10.9 \%)$ were in the $250-500 \mathrm{~nm}$ range. The majority of calcium spike amplitudes were in the $500-1000$ $\mathrm{nm}(61.7 \pm 11.9 \%)$ and $1000-2000 \mathrm{~nm}$ range $(30.9 \pm 11.5 \%)$ (Fig. $8 B$, Table, 1). Inhibition of CXCR4, $\mathrm{IP}_{3}$-sensitive calcium release, PKC, PKA, or nSMase2, but not CCR5, ryanodinesensitive calcium release, or de novo ceramide synthesis, prevented gp120 from increasing the amplitude of NMDA-evoked calcium bursts (Fig. 8C-L, Table, 1). Drugs used in these experiments did not significantly alter the amplitude of NMDA-evoked calcium responses (data not shown). Inhibition of sodium channels or voltage-operated calcium channels did not alter the amplitude of NMDA-evoked calcium bursts in control or gp120treated neurons (data not shown). Likewise, NMDA-evoked calcium responses in $\mathrm{Mg}$-free buffer were enhanced when neurons 
A

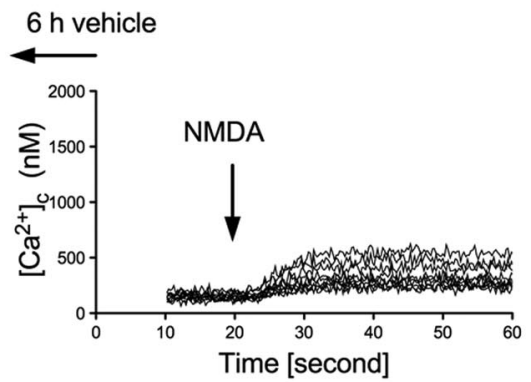

D

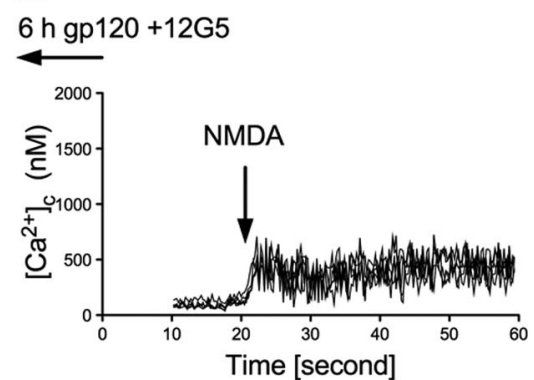

G

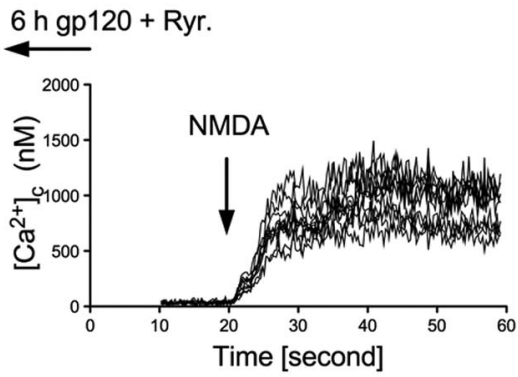

J

6 h gp $120+$ Chet.

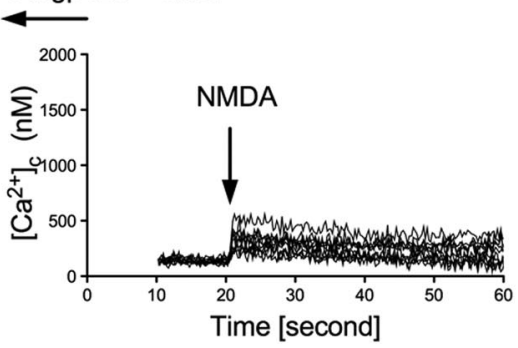

B

$6 \mathrm{~h} \mathrm{gp} 120$

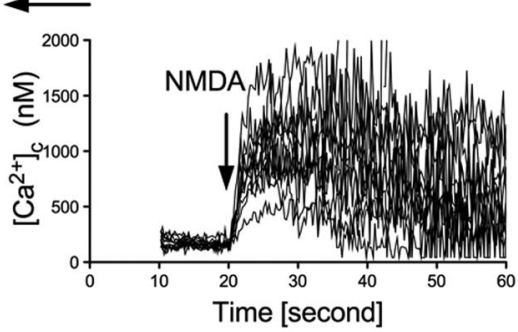

E

6 h gp120 +GW4869

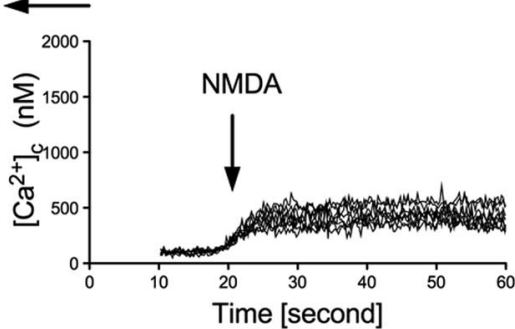

$\mathrm{H}$

6 h gp120 + Xesto.

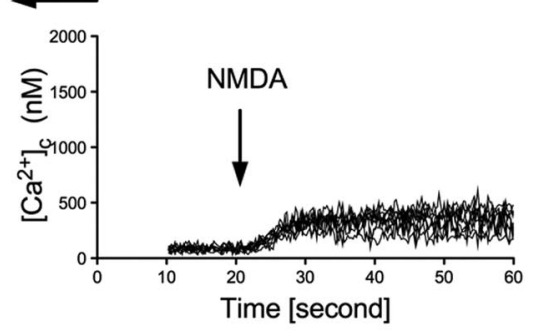

K

6 h gp120 +shRNA smpd3

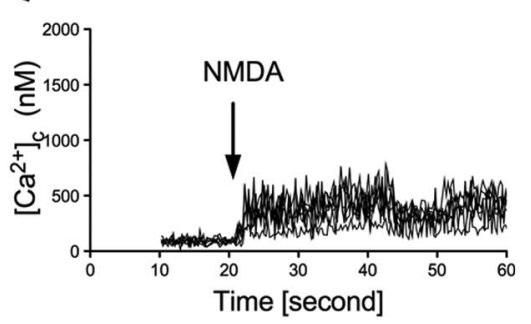

C

$6 \mathrm{~h} \mathrm{gp} 120+2 \mathrm{D} 7$

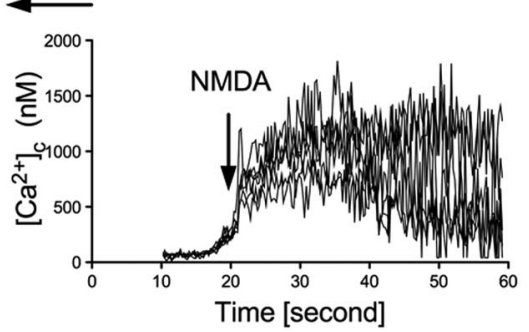

F

6 h gp $120+$ ISP-1

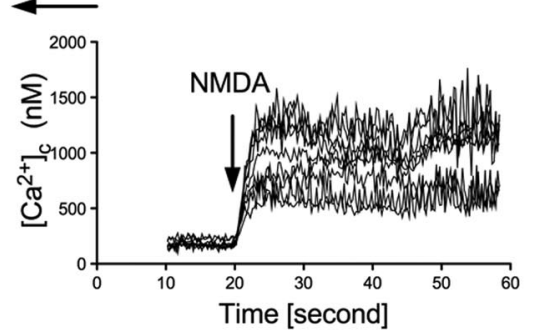

I

6 h gp120 +KT5720

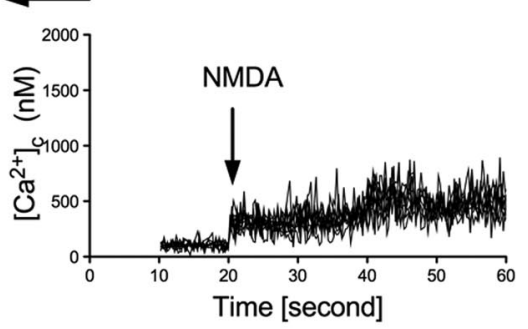

L

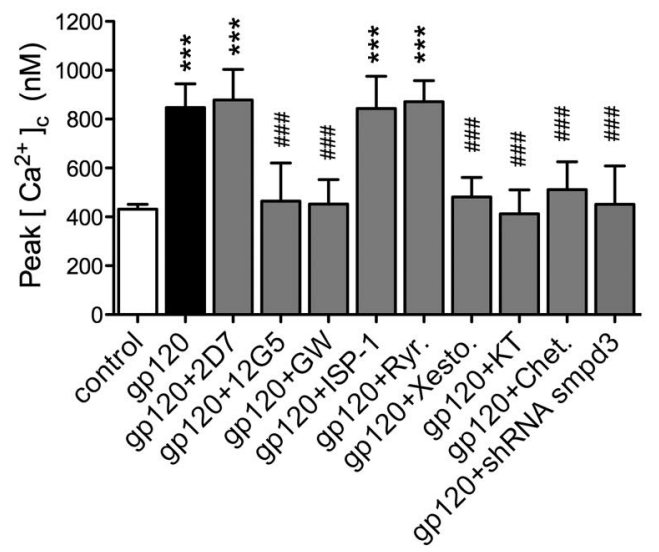

Figure 8. gp120 enhanced focal NMDA-evoked calcium bursts by promoting the forward traffic and surface clustering of NMDA receptors. Primary hippocampal neurons were loaded with the ratiometric calcium-sensitive dye fura- $2 \mathrm{AM}$, and images were acquired in microdomains located along neurites at the rate of five image pairs per second. Traces are representative experiments showing calcium spikes in neuritic microdomains evoked by brief application of NMDA (10 $\mu \mathrm{M})$ plus glycine (100 nM) in neurons pretreated for $6 \mathrm{~h}$ with vehicle $(\boldsymbol{A})$ or gp120 (B) (250 pM). In the remaining panels, cultures were treated with the indicated compounds for 30 min before gp 120, except for RNA interference experiments in which shRNA packaged into lentiviral vectors was applied $24 \mathrm{~h}$ before gp120. The treatments are as follows: $\boldsymbol{C}, 2 \mathrm{D7}$ (1:200), an antibody that blocks agonist binding to CCR5; $\boldsymbol{D}, 12 \mathrm{G5}$ (1:200), an antibody that blocks agonist binding to $X X C R 4 ; \boldsymbol{E}, \mathrm{GW} 4869(20 \mu \mathrm{M})$, an inhibitor of nSMase2; $\boldsymbol{F}$, ISP-1 (10 $\mu \mathrm{m})$, an inhibitor of serine palmitoyl transferase; $\boldsymbol{G}$, ryanodine (Ryr; $1 \mu \mathrm{M})$, a modulator of ryanodine receptors; $\boldsymbol{H}$, xestospongin $(X e s t 0 ; 15 \mu \mathrm{M})$, an inhibitor of $\mathrm{IP}_{3}$ receptors; $\boldsymbol{I}$, KT5720 $(0.6 \mu \mathrm{M})$, an inhibitor of PKA; $\boldsymbol{J}$, chelerythrine $(C h e t ; 1 \mu \mathrm{M})$, an inhibitor of PKC; $\boldsymbol{K}$, shRNA directed to silence nSMase2 (smpd3). $\boldsymbol{L}$, Summary data of average peak intracellular calcium increases evoked by NMDA plus glycine with the indicated pretreatments. Quantitative data are the average \pm SD of $30-45$ microdomains from each of four separate experiments. ${ }^{* * *} p<0.001$ compared with control; ${ }^{* \# \#} p<0.001$ compared with gp 120 . ANOVA with Tukey's post hoc comparisons. 
Table 1. HIV- gp120 shifted the frequency of NMDA-evoked calcium responses

\begin{tabular}{|c|c|c|c|c|}
\hline & $1000-2000 \mathrm{~mm} \mathrm{Ca}^{2+}$ & $500-1000 \mathrm{~mm} \mathrm{Ca}^{2+}$ & $250-500 \mathrm{~mm} \mathrm{Ca}^{2+}$ & $0-250 \mathrm{~mm} \mathrm{Ca}^{2+}$ \\
\hline Control & 0 & $17.75 \pm 9.17$ & $81.70 \pm 9.61$ & $0.55 \pm 1.21$ \\
\hline gp120 & $30.90 \pm 11.54^{* * *}$ & $61.73 \pm 11.92^{*}$ & $7.27 \pm 10.98^{* * *}$ & $0.10 \pm 0.30$ \\
\hline$\alpha-\mathrm{CCR} 5+$ gp120 & $31.94 \pm 16.16^{* * *}$ & $56.38 \pm 16.49$ & $3.09 \pm 2.69^{* * *}$ & $8.58 \pm 4.88$ \\
\hline$\alpha$-CXCR4 + gp120 & $4.70 \pm 6.28^{\# \#}$ & $28.58 \pm 16.18$ & $57.81 \pm 26.63^{\# \#}$ & $8.91 \pm 6.08$ \\
\hline GW4896 + gp120 & $0^{\# \# \#}$ & $28.50 \pm 33.59$ & $66.55 \pm 30.58^{\# \# \#}$ & $4.95 \pm 12.13$ \\
\hline ISP-1 + gp120 & $30.54 \pm 12.70^{* * *}$ & $53.37 \pm 18.32$ & $12.90 \pm 15.20^{* * *}$ & $3.16 \pm 5.32$ \\
\hline Ryanodine + gp120 & $30.46 \pm 14.59^{* * *}$ & $59.77 \pm 25.01$ & $4.27 \pm 4.67^{* * *}$ & $5.49 \pm 13.45$ \\
\hline Xestospongin + gp120 & $1.85 \pm 2.39^{\# \# \#}$ & $39.28 \pm 23.59$ & $47.55 \pm 25.74^{\#}$ & $10.42 \pm 11.32$ \\
\hline KT5720 + gp120 & $30.54 \pm 12.70^{* * *}$ & $53.36 \pm 18.32$ & $12.92 \pm 15.02$ & $3.16 \pm 5.31$ \\
\hline Chelerythrine + gp120 & $0^{\# \# \#}$ & $40.45 \pm 37.65$ & $56.74 \pm 37.65^{\# \#}$ & $2.81 \pm 6.88$ \\
\hline
\end{tabular}

Data show the percentage of NMDA-evoked calcium bursts in the indicated amplitude ranges. ${ }^{*} p<0.05,{ }^{* *} p<0.01,{ }^{* * *} p<0.001$ compared with control. ${ }^{\#} p<0.05,{ }^{\# \#} p<0.01$, ${ }^{\# \# \#} p<0.001$ compared with gp 120 .

A
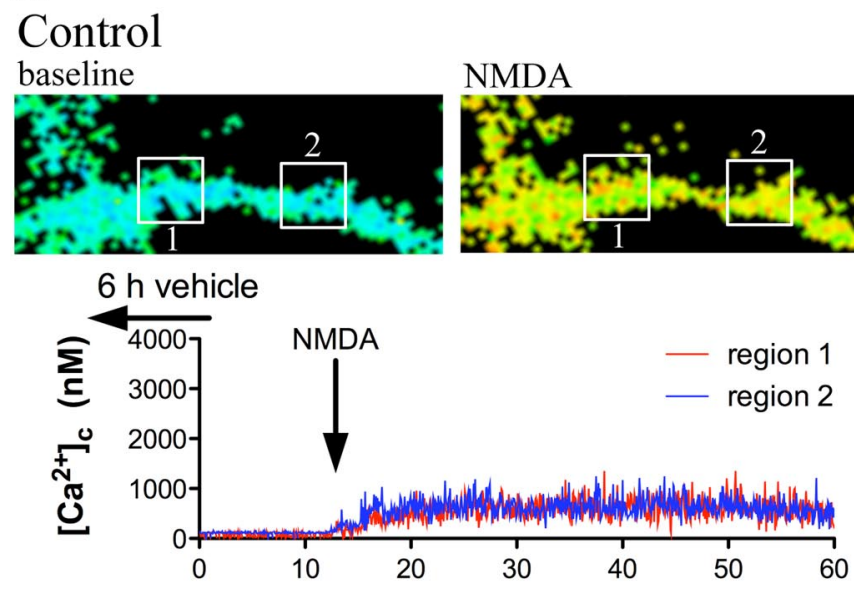

C

gp120
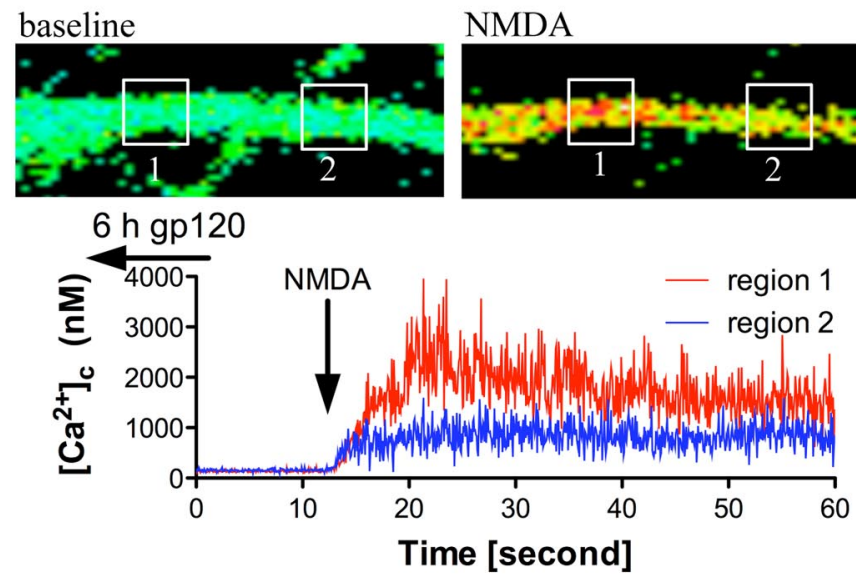

NMDA

NMDA
B
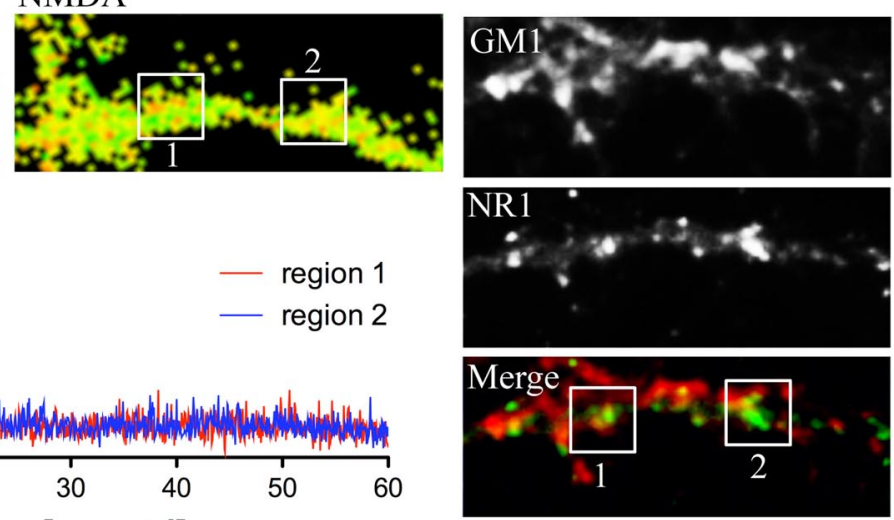

D
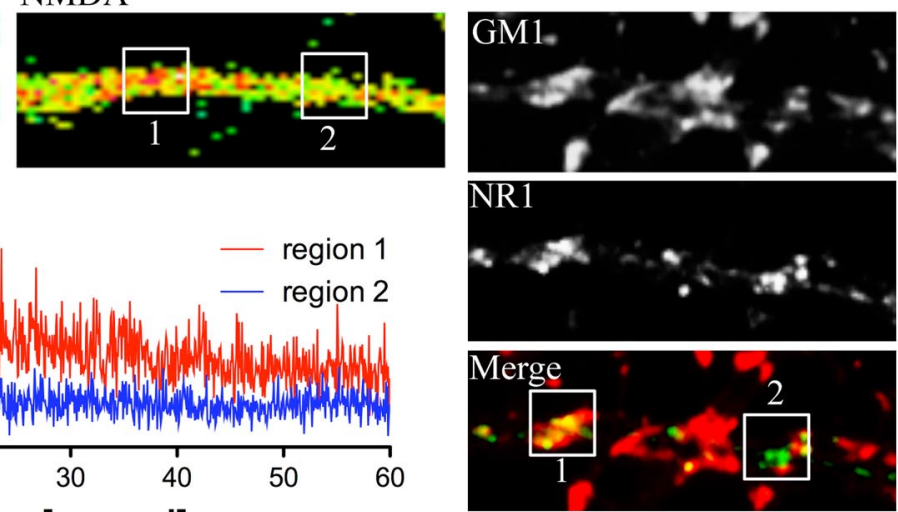

Figure 9. gp120 enhanced NMDA-evoked calcium bursts in membrane microdomains. Calcium measures were acquired at the rate of five image pairs per second in discrete regions $\left(\sim 1 \mu \mathrm{m}^{2}\right)$ located along dendrites of primary hippocampal neurons. A, In control conditions, brief applications of NMDA (10 $\mu$ M) plus glycine (100 nM) evoked calcium bursts along dendritic branches. Pseudocolor images show a snapshot of calcium concentrations at baseline and after a pulse of NMDA plus glycine. Increased color intensity represents increased calcium concentrations. Traces show calcium concentrations for the indicated regions of the dendrite. $\boldsymbol{B}$, Immunostaining of the same dendrite in $\boldsymbol{A}$, showing GM1, NR1, and the merged images (GM1 is red, NR1 is green, and colocalized regions appear yellow). Regions 1 and 2 of immunostained images correspond to the same regions of the calcium images. C, Pseudocolor images and associated traces depict baseline calcium concentrations and NMDA-evoked increases of calcium for the indicated regions of interest. Pretreatment of neurons for $6 \mathrm{~h}$ with gp120 (250 pM) enhanced NMDA-evoked calcium bursts in select regions of the membrane. $\boldsymbol{D}$, Immunostaining of the same dendrite shown in $\boldsymbol{C}$, demonstrating that NMDA-evoked calcium increases were enhanced in a membrane domain in which clusters of NR1 were located to GM1-immunopositive lipid rafts (region 1) but not in a membrane domain in which NR1 was located to a non-raft region (region 2). Results shown are representative of those obtained from three independent experiments.

were pretreated with gp120 for $6 \mathrm{~h}$, suggesting that the observed effects were not attributable to a general membrane depolarization induced by gp120 (data not shown). Next, we directly determined the focal location of NMDA-evoked calcium responses in relation to the raft versus non-raft location of NR1. In these experiments, NMDA-evoked calcium responses were recorded from focal dendritic regions, followed by fixation and immunostaining of cells to identify lipid rafts and NR1. After gp120 expo- 


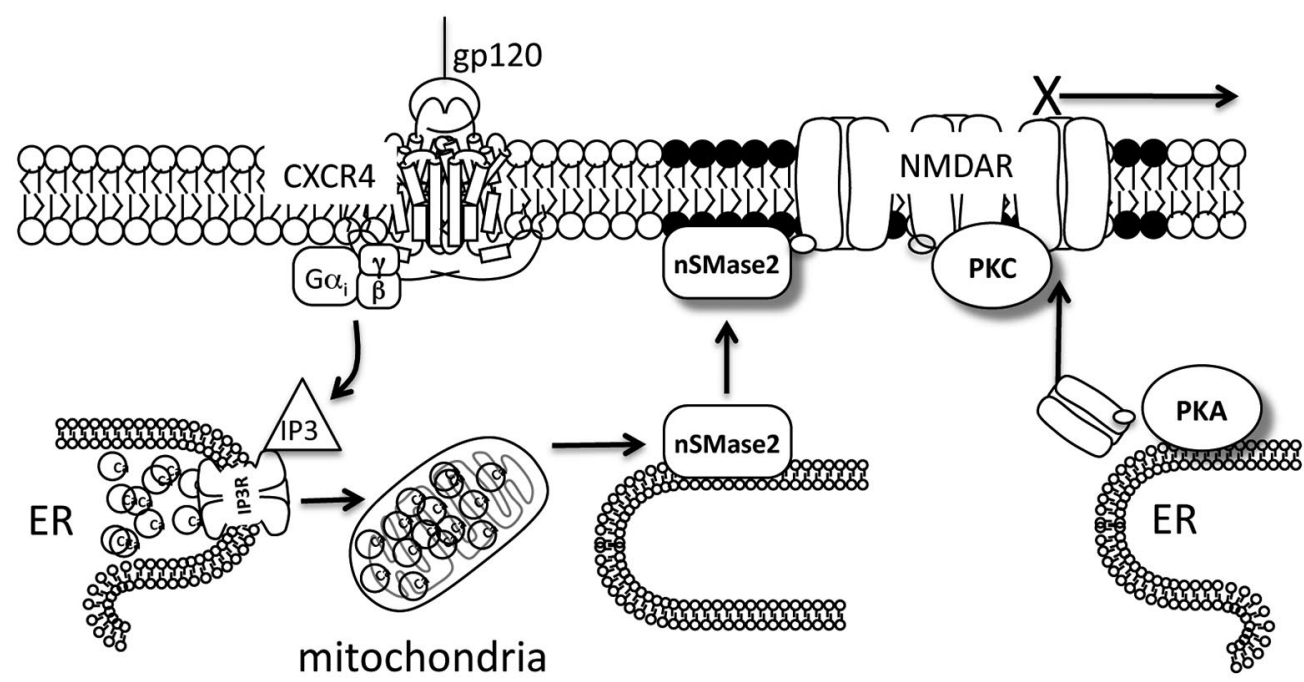

Figure 10. Summary of the mechanisms by which gp120 promotes forward trafficking and surface clustering of NMDA receptors in membrane microdomains. HIV-gp120 interacts with the chemokine receptor $C X C R 4$ to generate $\mathbb{P}_{3}$ that triggers $E R$ calcium release and perturbs mitochondrial function. The release of free radicals from mitochondria promotes the translocation of $\mathrm{nSMase} 2$ to the plasma membrane, where this enzyme converts sphingomyelin to ceramide. These alterations in membrane lipids increase the size and stabilize the structure of lipid rafts. Concurrently, HIV - gp120 promotes the forward traffic of NMDA receptors by increased PKA- and PKC-dependent phosphorylation of NR1 C-terminal serines 897 (to promote ER release) and 896 (important for surface expression). These surface-located receptors become clustered in enlarged and stabilized lipid rafts. As a result, NMDA-evoked calcium influx is enhanced in these membrane microdomains.

sures, NMDA-evoked calcium responses were slightly enhanced in non-raft regions of dendrites and were greatly potentiated in regions in which clusters of NR1 located to lipid rafts (Fig. 9A$D)$. These functional data are consistent with our molecular and biochemical findings that show gp120 enhanced the forward traffic, surface expression, and clustering of NMDA receptors that become sequestered in modified membrane microdomains.

\section{Discussion}

Numerous viral and non-viral products are thought to contribute to neuronal dysfunction and degeneration in the setting of HIV infection (Mattson et al., 2005; Irish et al., 2009). The viral coat protein gp120 is a potent neurotoxin with effects in the low picomolar range. In addition to binding CD4, different gp 120 isolates bind the chemokine receptors CXCR4 and CCR5. In the studies reported here, we used a strain of gp120 that interacts with CXCR4. Although both CXCR4 and CCR5 trophic strains of gp120 cause neuronal damage, CXCR4 binding strains of gp120 are potent neurotoxins. CXCR4-gp120 is toxic to neurons through indirect actions on glia that increase the release of inflammatory cytokines (and other small molecules such as arachidonic acid) and by direct actions on neurons mediated through CXCR4 (Dreyer and Lipton, 1995; Meucci and Miller, 1996; Meucci et al., 1998; Catani et al., 2000; Pandey and Bolsover, 2000; Khan et al., 2004; Geeraerts et al., 2006; Ronaldson and Bendayan, 2006). However, it is important to note that gp120 signaling through CXCR4 appears to be qualitatively different compared with CXCL12 (a natural ligand for CXCR4). For instance, CXCL12 has been shown to protect neurons from NMDA toxicity through actions that involve inhibition of NR2B expression and reductions in NMDA-evoked calcium responses (Khan et al., 2008; Nicolai et al., 2010). In contrast, HIV-gp120 is directly toxic to neurons by mechanisms that involve CXCR 4 and NMDA receptors (Wu et al., 1996; Hesselgesser et al., 1998; Meucci et al., 1998; Kaul and Lipton, 1999). One potential explanation for these differences is that these ligands differentially activate CXCR4. There are a number of residues throughout
CXCR4 that are specifically involved in interactions with gp120 that do not play a role in CXCL12 binding or signaling (Choi et al., 2005). Thus, it is not unexpected that downstream effects of CXCR4 signaling are quite different when stimulated by gp120 compared with CXCL12.

Despite considerable evidence that NMDA receptors are critical for gp120-induced neuronal damage (Lipton, 1992; Corasaniti et al., 1995; Toggas et al., 1996; Meucci et al., 1998), relatively little is known of the molecular mechanisms by which gp120 enhances NMDA receptor activity. Our data describe a detailed molecular mechanism in which gp120 directly interacts with neurons to enhance surface expression of NMDA receptors. We have identified three cooperative signaling pathways that contribute to this effect. First, gp120 enlarges and stabilizes membrane microdomains through actions that involve CXCR4, ER calcium, and a redox-sensitive translocation of nSMase2 to the plasma membrane. By catalyzing the hydrolysis of sphingomyelin to ceramide, nSMase2 facilitates the stabilization and enlargement of membrane microdomains. Second, gp120 signaling through PKA and PKC promotes phosphorylation of NR1 C-terminal serines 897 and 896 . These modifications promote the forward traffic and surface expression of NR1. Last, clusters of NR1 become sequestered at synapses in enlarged membrane microdomains, in which the receptors appear to unable to (or slow to) laterally disperse and internalize (Fig. 10).

Regulating the traffic of NMDA receptors is important for synaptic plasticity (Rao and Craig, 1997; Quinlan et al., 1999; Watt et al., 2000; Lan et al., 2001; Roche et al., 2001; Barria and Malinow, 2002; Nong et al., 2003; Lavezzari et al., 2004; Scott et al., 2004; Washbourne et al., 2004), and dysfunctions in NMDA receptor trafficking are thought to contribute to synaptic dysfunction in numerous neurological and psychiatric disorders, including schizophrenia, Alzheimer's disease, and Parkinson's disease (Waldron et al., 2008; Bagetta et al., 2010; Kristiansen et al., 2010). To this literature, we add evidence that, in the setting of HIV infection, the forward traffic of NMDA receptors is en- 
hanced, and these receptors become clustered in stabilized membrane microdomains.

NMDA receptors are tetramers that contain two NR1 subunits combined with NR2 (and NR3 in a small fraction of receptors). There is considerable diversity in NR1 because of alternate splicing of exons 5, 21, and 22, which result in at least eight protein variants that are differentially regulated to control forward trafficking (Horak and Wenthold, 2009). Exon 21 encodes four phosphorylation sites on threonine 879 and serines 896,897 , and 890 . PKA phosphorylation of serine 897 and PKC phosphorylation of serine 896 appear to be important for forward traffic, surface location, and clustering of NR1, whereas phosphorylation of serine 890 by PKC is important for dispersal of NR1 clusters (Tingley et al., 1997; Scott et al., 2001, 2003). In this study, we found that gp120 enhanced the phosphorylation of NR1 on serines 896, 897, and 890 in an ordered sequence. Phosphorylation of NR1 on serine 897 by PKA was rapid and presumably masked an ER retention signal. Phosphorylation of serine 896 by PKC occurred more slowly, likely at or near the plasma to regulate receptor insertion. Consistent with this data, PKA is known to regulate the phosphorylation of multiple ER proteins (Bugrim, 1999; Zhou et al., 2002; Procino et al., 2003; O'Connell et al., 2005), whereas PKC activation is associated with plasma membrane location (Bi et al., 2001; Bécart et al., 2003; Botto et al., 2007). HIV-gp120 can increase the activity of both PKA and PKC (Gupta et al., 1994; Zheng et al., 1999; Masci et al., 2003), and it would appear that both these activities are critical for the effect of gp120 to enhance the forward traffic and surface localization of NMDA receptors.

Protein location, scaffolding, and signal transduction are regulated in part through the dynamic modulation of membrane microdomains. Ceramide-rich microdomains can coalesce into larger platforms or disassemble into smaller components in the timescale of seconds to minutes (Simons and Gerl, 2010). The physical structure of membrane microdomains can be regulated by ceramide metabolism with important implications for synaptic function, including synapse formation, neurotransmitter release, receptor trafficking, and plasticity (Ito and Horigome, 1995; Furukawa and Mattson, 1998; Furuya et al., 1998; Inokuchi et al., 1998; Ping and Barrett, 1998; Brann et al., 1999; Coogan et al., 1999; Yang, 2000; Fasano et al., 2003; Wheeler et al., 2009). Our data suggest that ceramide generation by the sphingomyelin hydrolase nSMase2 played important roles in regulating the size and stability of membrane microdomains. Pharmacological inhibition or molecular knockdown of nSMase2 reduced the size of membrane microdomains. HIV-gp120 increased the size of and stabilized the structure of membrane microdomains by mechanisms that involved nSMase2. There are several properties of nSMase2 that suggest it is an important neuromodulator. nSMase2 is widely expressed in the brain (Hofmann et al., 2000; Aubin et al., 2005), with high expression in the hippocampus (see smpd3 at http://mouse.brain-map.org). Pharmacological inhibition or genetic mutation of nSMase2 decreases brain ceramide and impairs spatial and episodic-like memory in mice, suggesting that nSMase2 is an important regulator of events related to memory (Tabatadze et al., 2010). nSMase2 is required for NGFinduced neurite outgrowth and plays roles in some forms of synaptic plasticity (Riboni et al., 1995; Brann et al., 2002). Exogenous additions of nSMase2 selectively enhanced population spike amplitudes and fEPSP-postsynaptic potentiation of the CA3-CA1 Schaeffer collateral synapse, and nSMase2 activity was required for TNF $\alpha$-induced increases of EPSCs (Wheeler et al., 2009; Norman et al., 2010). These ceramide-induced enhance- ments of excitatory currents were typically transient and often followed by a sustained depression, likely as a result of endogenous regulatory mechanisms that limit the biological effects of this highly reactive lipid product (Furukawa and Mattson, 1998; Coogan et al., 1999; Yang, 2000; Davis et al., 2006; Tabarean et al., 2006). Indeed, exaggerated and prolonged elevations of ceramide can favor the activation of apoptotic pathways and have been associated with neurodegeneration (Haughey et al., 2004; Jana et al., 2009; Ben-David and Futerman, 2010).

In the current study, we found that gp120 increased ceramide over a timeframe of hours. This kinetic of ceramide generation increased the size and stabilized the structure of lipid rafts for prolonged periods of time and was associated with the sequestration of NMDA receptors into surface-located clusters. In addition to dysregulating the spatial and temporal features of NMDA-evoked calcium flux, this perturbation in NMDA receptor traffic would have important implications on associated signaling events. For instance, a recent study found that lipid-raft-located NMDARPSD95 complexes interacted with different signaling proteins compared with complexes isolated from soluble (non-raft) fractions. In particular, the amount of Src and Arc/Arg3.1 was greater and SynGAP and CaMKII were reduced in lipid raft fraction (Delint-Ramirez et al., 2010). These data suggest that, after gp 120 stimulation, a stabilized lipid raft complex would promote signaling through the Src signaling pathway. Consistent with these observations, HIV and gp120 are known to increase the activity of Src family tyrosine kinases and reduce CaMKII activity (Phipps et al., 1996; Geeraerts et al., 2006; Gupta et al., 2010). Because many components of signaling complexes are anchored to cellular membranes, it is likely that the enlargement and stabilization of membrane microdomains by gp 120 interferes with numerous signaling pathways that rely on shifts in membrane lipid composition to regulate signal switching. Thus, therapeutics to selectively target enzymes involved in ceramide metabolism may preserve neuronal function in the setting of HANDs and potentially other neurodegenerative conditions.

\section{References}

Achim CL, Adame A, Dumaop W, Everall IP, Masliah E; Neurobehavioral Research Center (2009) Increased accumulation of intraneuronal amyloid beta in HIV-infected patients. J Neuroimmune Pharmacol 4:190-199.

Ances BM, Vaida F, Yeh MJ, Liang CL, Buxton RB, Letendre S, McCutchan JA, Ellis RJ (2010) HIV infection and aging independently affect brain function as measured by functional magnetic resonance imaging. J Infect Dis 201:336-340.

Antinori A, Arendt G, Becker JT, Brew BJ, Byrd DA, Cherner M, Clifford DB, Cinque P, Epstein LG, Goodkin K, Gisslen M, Grant I, Heaton RK, Joseph J, Marder K, Marra CM, McArthur JC, Nunn M, Price RW, Pulliam L, Robertson KR, Sacktor N, Valcour V, Wojna VE (2007) Updated research nosology for HIV-associated neurocognitive disorders. Neurology 69:1789-1799.

Aubin I, Adams CP, Opsahl S, Septier D, Bishop CE, Auge N, Salvayre R, Negre-Salvayre A, Goldberg M, Guénet JL, Poirier C (2005) A deletion in the gene encoding sphingomyelin phosphodiesterase 3 (Smpd3) results in osteogenesis and dentinogenesis imperfecta in the mouse. Nat Genet 37:803-805.

Bagetta V, Ghiglieri V, Sgobio C, Calabresi P, Picconi B (2010) Synaptic dysfunction in Parkinson's disease. Biochem Soc Trans 38:493-497.

Bandaru VV, McArthur JC, Sacktor N, Cutler RG, Knapp EL, Mattson MP, Haughey NJ (2007) Associative and predictive biomarkers of dementia in HIV-1-infected patients. Neurology 68:1481-1487.

Bandaru VV, Troncoso J, Wheeler D, Pletnikova O, Wang J, Conant K, Haughey NJ (2009) ApoE4 disrupts sterol and sphingolipid metabolism in Alzheimer's but not normal brain. Neurobiol Aging 30:591-599.

Barria A, Malinow R (2002) Subunit-specific NMDA receptor trafficking to synapses. Neuron 35:345-353. 
Bécart S, Setterblad N, Ostrand-Rosenberg S, Ono SJ, Charron D, Mooney N (2003) Intracytoplasmic domains of MHC class II molecules are essential for lipid-raft-dependent signaling. J Cell Sci 116:2565-2575.

Ben-David O, Futerman AH (2010) The role of the ceramide acyl chain length in neurodegeneration: involvement of ceramide synthases. Neuromolecular Med 12:341-350.

Besshoh S, Bawa D, Teves L, Wallace MC, Gurd JW (2005) Increased phosphorylation and redistribution of NMDA receptors between synaptic lipid rafts and post-synaptic densities following transient global ischemia in the rat brain. J Neurochem 93:186-194.

Bi K, Tanaka Y, Coudronniere N, Sugie K, Hong S, van Stipdonk MJ, Altman A (2001) Antigen-induced translocation of PKC-theta to membrane rafts is required for T cell activation. Nat Immunol 2:556-563.

Botto L, Masserini M, Palestini P (2007) Changes in the composition of detergent-resistant membrane domains of cultured neurons following protein kinase C activation. J Neurosci Res 85:443-450.

Brann AB, Scott R, Neuberger Y, Abulafia D, Boldin S, Fainzilber M, Futerman AH (1999) Ceramide signaling downstream of the p75 neurotrophin receptor mediates the effects of nerve growth factor on outgrowth of cultured hippocampal neurons. J Neurosci 19:8199-8206.

Brann AB, Tcherpakov M, Williams IM, Futerman AH, Fainzilber M (2002) Nerve growth factor-induced p75-mediated death of cultured hippocampal neurons is age-dependent and transduced through ceramide generated by neutral sphingomyelinase. J Biol Chem 277:9812-9818.

Brew BJ, Crowe SM, Landay A, Cysique LA, Guillemin G (2009) Neurodegeneration and ageing in the HAART era. J Neuroimmune Pharmacol 4:163-174.

Bugrim AE (1999) Regulation of $\mathrm{Ca}^{2+}$ release by cAMP-dependent protein kinase. A mechanism for agonist-specific calcium signaling? Cell Calcium 25:219-226.

Cardenas VA, Meyerhoff DJ, Studholme C, Kornak J, Rothlind J, Lampiris H, Neuhaus J, Grant RM, Chao LL, Truran D, Weiner MW (2009) Evidence for ongoing brain injury in human immunodeficiency viruspositive patients treated with antiretroviral therapy. J Neurovirol 15:324-333.

Catani MV, Corasaniti MT, Navarra M, Nisticò G, Finazzi-Agrò A, Melino G (2000) gp120 induces cell death in human neuroblastoma cells through the CXCR4 and CCR5 chemokine receptors. J Neurochem 74:2373-2379.

Chang L, Wong V, Nakama H, Watters M, Ramones D, Miller EN, Cloak C, Ernst T (2008) Greater than age-related changes in brain diffusion of HIV patients after 1 year. J Neuroimmune Pharmacol 3:265-274.

Choi WT, Tian S, Dong CZ, Kumar S, Liu D, Madani N, An J, Sodroski JG, Huang Z (2005) Unique ligand binding sites on CXCR4 probed by a chemical biology approach: implications for the design of selective human immunodeficiency virus type 1 inhibitors. J Virol 79:15398-15404.

Cohen RA, Harezlak J, Gongvatana A, Buchthal S, Schifitto G, Clark U, Paul R, Taylor M, Thompson P, Tate D, Alger J, Brown M, Zhong J, Campbell T, Singer E, Daar E, McMahon D, Tso Y, Yiannoutsos CT, Navia B; HIV Neuroimaging Consortium (2010) Cerebral metabolite abnormalities in human immunodeficiency virus are associated with cortical and subcortical volumes. J Neurovirol 16:435-444.

Coogan AN, O’Neill LA, O'Connor JJ (1999) The P38 mitogen-activated protein kinase inhibitor SB203580 antagonizes the inhibitory effects of interleukin-1beta on long-term potentiation in the rat dentate gyrus in vitro. Neuroscience 93:57-69.

Corasaniti MT, Melino G, Navarra M, Garaci E, Finazzi-Agrò A, Nisticò G (1995) Death of cultured human neuroblastoma cells induced by HIV-1 gp120 is prevented by NMDA receptor antagonists and inhibitors of nitric oxide and cyclooxygenase. Neurodegeneration 4:315-321.

Corasaniti MT, Strongoli MC, Piccirilli S, Nisticò R, Costa A, Bilotta A, Turano P, Finazzi-Agrò A, Bagetta G (2000) Apoptosis induced by gp120 in the neocortex of rat involves enhanced expression of cyclooxygenase type 2 and is prevented by NMDA receptor antagonists and by the 21-aminosteroid U-74389G. Biochem Biophys Res Commun 274:664669.

Davis CN, Tabarean I, Gaidarova S, Behrens MM, Bartfai T (2006) IL-1beta induces a MyD88-dependent and ceramide-mediated activation of Src in anterior hypothalamic neurons. J Neurochem 98:1379-1389.

Day CA, Kenworthy AK (2009) Tracking microdomain dynamics in cell membranes. Biochim Biophys Acta 1788:245-253.

Delint-Ramirez I, Fernández E, Bayés A, Kicsi E, Komiyama NH, Grant SG (2010) In vivo composition of NMDA receptor signaling complexes dif- fers between membrane subdomains and is modulated by PSD-95 and PSD-93. J Neurosci 30:8162-8170.

Dhillon NK, Peng F, Bokhari S, Callen S, Shin SH, Zhu X, Kim KJ, Buch SJ (2008) Cocaine-mediated alteration in tight junction protein expression and modulation of CCL2/CCR2 axis across the blood-brain barrier: implications for HIV-dementia. J Neuroimmune Pharmacol 3:52-56.

Dreyer EB, Lipton SA (1995) The coat protein gp120 of HIV-1 inhibits astrocyte uptake of excitatory amino acids via macrophage arachidonic acid. Eur J Neurosci 7:2502-2507.

Dreyer EB, Kaiser PK, Offermann JT, Lipton SA (1990) HIV-1 coat protein neurotoxicity prevented by calcium channel antagonists. Science 248:364-367.

El-Hage N, Wu G, Wang J, Ambati J, Knapp PE, Reed JL, Bruce-Keller AJ, Hauser KF (2006) HIV-1 Tat and opiate-induced changes in astrocytes promote chemotaxis of microglia through the expression of MCP-1 and alternative chemokines. Glia 53:132-146.

Fasano C, Miolan JP, Niel JP (2003) Modulation by C2 ceramide of the nicotinic transmission within the coeliac ganglion in the rabbit. Neuroscience 116:753-759.

Fischer-Smith T, Bell C, Croul S, Lewis M, Rappaport J (2008) Monocyte/ macrophage trafficking in acquired immunodeficiency syndrome encephalitis: lessons from human and nonhuman primate studies. J Neurovirol 14:318-326.

Füllekrug J, Simons K (2004) Lipid rafts and apical membrane traffic. Ann N Y Acad Sci 1014:164-169.

Furukawa K, Mattson MP (1998) The transcription factor NF-kappaB mediates increases in calcium currents and decreases in NMDA- and AMPA/ kainate-induced currents induced by tumor necrosis factor-alpha in hippocampal neurons. J Neurochem 70:1876-1886.

Furuya S, Mitoma J, Makino A, Hirabayashi Y (1998) Ceramide and its interconvertible metabolite sphingosine function as indispensable lipid factors involved in survival and dendritic differentiation of cerebellar Purkinje cells. J Neurochem 71:366-377.

Geeraerts T, Deiva K, M'sika I, Salim H, Héry C, Tardieu M (2006) Effects of SDF-1alpha and gp120IIIB on apoptotic pathways in SK-N-SH neuroblastoma cells. Neurosci Lett 399:115-120.

Gelman BB (2007) The neuropathology of HIV. Handb Clin Neurol 85:301-317.

Gongvatana A, Schweinsburg BC, Taylor MJ, Theilmann RJ, Letendre SL, Alhassoon OM, Jacobus J, Woods SP, Jernigan TL, Ellis RJ, Frank LR, Grant I; Charter Group (2009) White matter tract injury and cognitive impairment in human immunodeficiency virus-infected individuals. J Neurovirol 15:187-195.

Gorry PR, Bristol G, Zack JA, Ritola K, Swanstrom R, Birch CJ, Bell JE, Bannert N, Crawford K, Wang H, Schols D, De Clercq E, Kunstman K, Wolinsky SM, Gabuzda D (2001) Macrophage tropism of human immunodeficiency virus type 1 isolates from brain and lymphoid tissues predicts neurotropism independent of coreceptor specificity. J Virol 75: 10073-10089.

Gray F, Bazille C, Adle-Biassette H, Mikol J, Moulignier A, Scaravilli F (2005) Central nervous system immune reconstitution disease in acquired immunodeficiency syndrome patients receiving highly active antiretroviral treatment. J Neurovirol 11 [Suppl 3]:16-22.

Gupta RG, Kelly KM, Helke KL, Queen SE, Karper JM, Dorsey JL, Brice AK, Adams RJ, Tarwater PM, Kolson DL, Mankowski JL (2010) HIV and SIV induce alterations in CNS CaMKII expression and activation: a potential mechanism for cognitive impairment. Am J Pathol 176:27762784.

Gupta S, Aggarwal S, Kim C, Gollapudi S (1994) Human immunodeficiency virus-1 recombinant gp120 induces changes in protein kinase $\mathrm{C}$ isozymes: a preliminary report. Int J Immunopharmacol 16:197-204.

Haughey NJ (2010) Sphingolipids in neurodegeneration. Neuromolecular Med 12:301-305.

Haughey NJ, Cutler RG, Tamara A, McArthur JC, Vargas DL, Pardo CA, Turchan J, Nath A, Mattson MP (2004) Perturbation of sphingolipid metabolism and ceramide production in HIV-dementia. Ann Neurol $55: 257-267$

Hesselgesser J, Taub D, Baskar P, Greenberg M, Hoxie J, Kolson DL, Horuk R (1998) Neuronal apoptosis induced by HIV-1 gp120 and the chemokine SDF-1 alpha is mediated by the chemokine receptor CXCR4. Curr Biol 8:595-598.

Hofmann K, Tomiuk S, Wolff G, Stoffel W (2000) Cloning and character- 
ization of the mammalian brain-specific, $\mathrm{Mg}^{2+}$-dependent neutral sphingomyelinase. Proc Natl Acad Sci U S A 97:5895-5900.

Höke A, Morris M, Haughey NJ (2009) GPI-1046 protects dorsal root ganglia from gp 120-induced axonal injury by modulating store-operated calcium entry. J Peripher Nerv Syst 14:27-35.

Horak M, Wenthold RJ (2009) Different roles of C-terminal cassettes in the trafficking of full-length NR1 subunits to the cell surface. J Biol Chem 284:9683-9691.

Inokuchi J, Mizutani A, Jimbo M, Usuki S, Yamagishi K, Mochizuki H, Muramoto K, Kobayashi K, Kuroda Y, Iwasaki K, Ohgami Y, Fujiwara M (1998) A synthetic ceramide analog (L-PDMP) up-regulates neuronal function. Ann N Y Acad Sci 845:219-224.

Irish BP, Khan ZK, Jain P, Nonnemacher MR, Pirrone V, Rahman S, Rajagopalan N, Suchitra JB, Mostoller K, Wigdahl B (2009) Molecular mechanisms of neurodegenerative diseases induced by human retroviruses: a review. Am J Infect Dis 5:231-258.

Ito A, Horigome K (1995) Ceramide prevents neuronal programmed cell death induced by nerve growth factor deprivation. J Neurochem 65:463-466.

Jana A, Pahan K (2004) Human immunodeficiency virus type 1 gp120 induces apoptosis in human primary neurons through redox-regulated activation of neutral sphingomyelinase. J Neurosci 24:9531-9540.

Jana A, Hogan EL, Pahan K (2009) Ceramide and neurodegeneration: susceptibility of neurons and oligodendrocytes to cell damage and death. J Neurol Sci 278:5-15.

Kaul M, Lipton SA (1999) Chemokines and activated macrophages in HIV gp120-induced neuronal apoptosis. Proc Natl Acad Sci U S A 96:8212-8216

Khan MZ, Brandimarti R, Patel JP, Huynh N, Wang J, Huang Z, Fatatis A, Meucci O (2004) Apoptotic and antiapoptotic effects of CXCR4: is it a matter of intrinsic efficacy? Implications for HIV neuropathogenesis. AIDS Res Hum Retroviruses 20:1063-1071.

Khan MZ, Brandimarti R, Shimizu S, Nicolai J, Crowe E, Meucci O (2008) The chemokine CXCL12 promotes survival of postmitotic neurons by regulating $\mathrm{Rb}$ protein. Cell Death Differ 15:1663-1672.

Khanlou N, Moore DJ, Chana G, Cherner M, Lazzaretto D, Dawes S, Grant I, Masliah E, Everall IP; HNRC Group (2009) Increased frequency of alpha-synuclein in the substantia nigra in human immunodeficiency virus infection. J Neurovirol 15:131-138.

Kristiansen LV, Patel SA, Haroutunian V, Meador-Woodruff JH (2010) Expression of the NR2B-NMDA receptor subunit and its Tbr-1/CINAP regulatory proteins in postmortem brain suggest altered receptor processing in schizophrenia. Synapse 64:495-502.

Lan JY, Skeberdis VA, Jover T, Grooms SY, Lin Y, Araneda RC, Zheng X, Bennett MV, Zukin RS (2001) Protein kinase C modulates NMDA receptor trafficking and gating. Nat Neurosci 4:382-390.

Lavezzari G, McCallum J, Dewey CM, Roche KW (2004) Subunit-specific regulation of NMDA receptor endocytosis. J Neurosci 24:6383-6391.

Levy M, Castillo SS, Goldkorn T (2006) nSMase2 activation and trafficking are modulated by oxidative stress to induce apoptosis. Biochem Biophys Res Commun 344:900-905.

Lipton SA (1992) Memantine prevents HIV coat protein-induced neuronal injury in vitro. Neurology 42:1403-1405.

Lipton SA, Sucher NJ, Kaiser PK, Dreyer EB (1991) Synergistic effects of HIV coat protein and NMDA receptor-mediated neurotoxicity. Neuron 7:111-118.

Liu Y, Tang XP, McArthur JC, Scott J, Gartner S (2000) Analysis of human immunodeficiency virus type 1 gp160 sequences from a patient with HIV dementia: evidence for monocyte trafficking into brain. J Neurovirol 6 [Suppl 1]:S70-S81.

Masci AM, Galgani M, Cassano S, De Simone S, Gallo A, De Rosa V, Zappacosta S, Racioppi L (2003) HIV-1 gp120 induces anergy in naive T lymphocytes through CD4-independent protein kinase-A-mediated signaling. J Leukoc Biol 74:1117-1124.

Mattson MP, Haughey NJ, Nath A (2005) Cell death in HIV dementia. Cell Death Differ 12 [Suppl 1]:893-904.

McArthur JC, Steiner J, Sacktor N, Nath A (2010) Human immunodeficiency virus-associated neurocognitive disorders: mind the gap. Ann Neurol 67:699-714.

McMurtray A, Nakamoto B, Shikuma C, Valcour V (2008) Cortical atrophy and white matter hyperintensities in HIV: the Hawaii Aging with HIV Cohort Study. J Stroke Cerebrovasc Dis 17:212-217.
Medina I, Ghose S, Ben-Ari Y (1999) Mobilization of intracellular calcium stores participates in the rise of $\left[\mathrm{Ca}^{2+}\right]_{\mathrm{i}}$ and the toxic actions of the HIV coat protein GP120. Eur J Neurosci 11:1167-1178.

Meucci O, Miller RJ (1996) gp120-induced neurotoxicity in hippocampal pyramidal neuron cultures: protective action of TGF- $\beta 1$. J Neurosci 16:4080-4088.

Meucci O, Fatatis A, Simen AA, Bushell TJ, Gray PW, Miller RJ (1998) Chemokines regulate hippocampal neuronal signaling and gp120 neurotoxicity. Proc Natl Acad Sci U S A 95:14500-14505.

Miller RF, Isaacson PG, Hall-Craggs M, Lucas S, Gray F, Scaravilli F, An SF (2004) Cerebral CD8 + lymphocytosis in HIV-1 infected patients with immune restoration induced by HAART. Acta Neuropathol 108:17-23.

Nicolai J, Burbassi S, Rubin J, Meucci O (2010) CXCL12 inhibits expression of the NMDA receptor's NR2B subunit through a histone deacetylasedependent pathway contributing to neuronal survival. Cell Death Dis 1:e33.

Nong Y, Huang YQ, Ju W, Kalia LV, Ahmadian G, Wang YT, Salter MW (2003) Glycine binding primes NMDA receptor internalization. Nature 422:302-307.

Norman E, Cutler RG, Flannery R, Wang Y, Mattson MP (2010) Plasma membrane sphingomyelin hydrolysis increases hippocampal neuron excitability by sphingosine-1-phosphate mediated mechanisms. J Neurochem 114:430-439.

O'Connell AD, Leng Q, Dong K, MacGregor GG, Giebisch G, Hebert SC (2005) Phosphorylation-regulated endoplasmic reticulum retention signal in the renal outer-medullary K+ channel (ROMK). Proc Natl Acad Sci U S A 102:9954-9959.

Owen DM, Williamson D, Rentero C, Gaus K (2009) Quantitative microscopy: protein dynamics and membrane organisation. Traffic 10:962-971.

Pandey V, Bolsover SR (2000) Immediate and neurotoxic effects of HIV protein gp120 act through CXCR4 receptor. Biochem Biophys Res Commun 274:212-215.

Pelle MT, Bazille C, Gray F (2008) Neuropathology and HIV dementia. Handb Clin Neurol 89:807-818.

Phipps DJ, Read SE, Piovesan JP, Mills GB, Branch DR (1996) HIV infection in vitro enhances the activity of src-family protein tyrosine kinases. AIDS 10:1191-1198.

Ping SE, Barrett GL (1998) Ceramide can induce cell death in sensory neurons, whereas ceramide analogues and sphingosine promote survival. J Neurosci Res 54:206-213.

Procino G, Carmosino M, Marin O, Brunati AM, Contri A, Pinna LA, Mannucci R, Nielsen S, Kwon TH, Svelto M, Valenti G (2003) Ser-256 phosphorylation dynamics of Aquaporin 2 during maturation from the ER to the vesicular compartment in renal cells. FASEB J 17:1886-1888.

Quinlan EM, Philpot BD, Huganir RL, Bear MF (1999) Rapid, experiencedependent expression of synaptic NMDA receptors in visual cortex in vivo. Nat Neurosci 2:352-357.

Ramirez SH, Potula R, Fan S, Eidem T, Papugani A, Reichenbach N, Dykstra H, Weksler BB, Romero IA, Couraud PO, Persidsky Y (2009) Methamphetamine disrupts blood-brain barrier function by induction of oxidative stress in brain endothelial cells. J Cereb Blood Flow Metab 29:1933-1945.

Rao A, Craig AM (1997) Activity regulates the synaptic localization of the NMDA receptor in hippocampal neurons. Neuron 19:801-812.

Riboni L, Prinetti A, Bassi R, Caminiti A, Tettamanti G (1995) A mediator role of ceramide in the regulation of neuroblastoma Neuro2a cell differentiation. J Biol Chem 270:26868-26875.

Roche KW, Standley S, McCallum J, Dune Ly C, Ehlers MD, Wenthold RJ (2001) Molecular determinants of NMDA receptor internalization. Nat Neurosci 4:794-802.

Ronaldson PT, Bendayan R (2006) HIV-1 viral envelope glycoprotein gp120 triggers an inflammatory response in cultured rat astrocytes and regulates the functional expression of P-glycoprotein. Mol Pharmacol 70:1087-1098.

Scott DB, Blanpied TA, Swanson GT, Zhang C, Ehlers MD (2001) An NMDA receptor ER retention signal regulated by phosphorylation and alternative splicing. J Neurosci 21:3063-3072.

Scott DB, Blanpied TA, Ehlers MD (2003) Coordinated PKA and PKC phosphorylation suppresses RXR-mediated ER retention and regulates the surface delivery of NMDA receptors. Neuropharmacology 45:755-767.

Scott DB, Michailidis I, Mu Y, Logothetis D, Ehlers MD (2004) Endocytosis 
and degradative sorting of NMDA receptors by conserved membraneproximal signals. J Neurosci 24:7096-7109.

Simioni S, Cavassini M, Annoni JM, Rimbault Abraham A, Bourquin I, Schiffer V, Calmy A, Chave JP, Giacobini E, Hirschel B, Du Pasquier RA (2010) Cognitive dysfunction in HIV patients despite long-standing suppression of viremia. AIDS 24:1243-1250.

Simons K, Gerl MJ (2010) Revitalizing membrane rafts: new tools and insights. Nat Rev Mol Cell Biol 11:688-699.

Stahelin RV (2009) Lipid binding domains: more than simple lipid effectors. J Lipid Res [Suppl] 50:S299-S304.

Swartz KJ (2008) Sensing voltage across lipid membranes. Nature 456:891-897.

Tabarean IV, Korn H, Bartfai T (2006) Interleukin-1beta induces hyperpolarization and modulates synaptic inhibition in preoptic and anterior hypothalamic neurons. Neuroscience 141:1685-1695.

Tabatadze N, Savonenko A, Song H, Bandaru VV, Chu M, Haughey NJ (2010) Inhibition of neutral sphingomyelinase-2 perturbs brain sphingolipid balance and spatial memory in mice. J Neurosci Res 88:2940-2951.

Tingley WG, Ehlers MD, Kameyama K, Doherty C, Ptak JB, Riley CT, Huganir RL (1997) Characterization of protein kinase A and protein kinase C phosphorylation of the $N$-methyl-D-aspartate receptor NR1 subunit using phosphorylation site-specific antibodies. J Biol Chem 272:5157-5166.

Toggas SM, Masliah E, Mucke L (1996) Prevention of HIV-1 gp120induced neuronal damage in the central nervous system of transgenic mice by the NMDA receptor antagonist memantine. Brain Res 706:303-307.

Toth PT, Ren D, Miller RJ (2004) Regulation of CXCR4 receptor dimerization by the chemokine SDF-1alpha and the HIV-1 coat protein gp120: a fluorescence resonance energy transfer (FRET) study. J Pharmacol Exp Ther 310:8-17.

Tozzi V, Balestra P, Bellagamba R, Corpolongo A, Salvatori MF, ViscoComandini U, Vlassi C, Giulianelli M, Galgani S, Antinori A, Narciso P (2007) Persistence of neuropsychologic deficits despite long-term highly active antiretroviral therapy in patients with HIV-related neurocognitive impairment: prevalence and risk factors. J Acquir Immune Defic Syndr $45: 174-182$
Ushijima H, Ando S, Kunisada T, Schröder HC, Klöcking HP, Kijjoa A, Müller WE (1993) HIV-1 gp120 and NMDA induce protein kinase C translocation differentially in rat primary neuronal cultures. J Acquir Immune Defic Syndr 6:339-343.

Valcour V, Watters MR, Williams AE, Sacktor N, McMurtray A, Shikuma C (2008) Aging exacerbates extrapyramidal motor signs in the era of highly active antiretroviral therapy. J Neurovirol 14:362-367.

Waldron E, Heilig C, Schweitzer A, Nadella N, Jaeger S, Martin AM, Weggen S, Brix K, Pietrzik CU (2008) LRP1 modulates APP trafficking along early compartments of the secretory pathway. Neurobiol Dis 31:188-197.

Washbourne P, Liu XB, Jones EG, McAllister AK (2004) Cycling of NMDA receptors during trafficking in neurons before synapse formation. J Neurosci 24:8253-8264.

Watt AJ, van Rossum MC, MacLeod KM, Nelson SB, Turrigiano GG (2000) Activity coregulates quantal AMPA and NMDA currents at neocortical synapses. Neuron 26:659-670.

Wheeler D, Knapp E, Bandaru VV, Wang Y, Knorr D, Poirier C, Mattson MP, Geiger JD, Haughey NJ (2009) Tumor necrosis factor $\alpha$ induced neutral sphingomyelinase-2 modulates synaptic plasticity by controlling the membrane insertion of NMDA receptors. J Neurochem 109:1237-1249.

Wu P, Price P, Du B, Hatch WC, Terwilliger EF (1996) Direct cytotoxicity of HIV-1 envelope protein gp120 on human NT neurons. Neuroreport 7:1045-1049.

Yang SN (2000) Ceramide-induced sustained depression of synaptic currents mediated by ionotropic glutamate receptors in the hippocampus: an essential role of postsynaptic protein phosphatases. Neuroscience 96:253-258.

Yao H, Duan M, Buch S (2011) Cocaine-mediated induction of plateletderived growth factor: implication for increased vascular permeability. Blood 117:2538-2547.

Zheng J, Thylin MR, Ghorpade A, Xiong H, Persidsky Y, Cotter R, Niemann D, Che M, Zeng YC, Gelbard HA, Shepard RB, Swartz JM, Gendelman HE (1999) Intracellular CXCR4 signaling, neuronal apoptosis and neuropathogenic mechanisms of HIV-1-associated dementia. J Neuroimmunol 98:185-200.

Zhou J, Shin HG, Yi J, Shen W, Williams CP, Murray KT (2002) Phosphorylation and putative ER retention signals are required for protein kinase A-mediated potentiation of cardiac sodium current. Circ Res 91:540-546. 